\title{
Evolution of microstructure in compacted London Clay during wetting and loading
}

\author{
R. MONROY*, L. ZDRAVKOVIC $\dagger$ and A. RIDLEY $\ddagger$
}

The influence of fabric on mechanical behaviour is explicitly considered in some of the current constitutive models for unsaturated soils. These are based on assumptions regarding the interaction between different levels of structure, which still require experimental validation. A study has been carried out to investigate the evolution of fabric in a compacted natural clay during wetting and loading, and the results are presented in this paper. Samples of London Clay were statically compacted to the same initial conditions, dry of optimum moisture content in a Proctor plot, and subsequently taken along complex stress paths involving wetting, loading, or a combination of both. Mercury intrusion porosimetry (MIP) and environmental scanning electron microscopy (ESEM) microstructure investigations were carried out to observe and quantify the change in fabric associated with each path. The soil fabric was observed to change from an aggregate to a matrix type structure along all wetting paths. This transition was found to take place only when the suction was reduced to a value close to zero $\mathrm{kPa}$. Results also showed that fabric changes during yielding were stress path-dependent. It was not possible to find a correspondence between the volume of free porosity and the volume of intra-aggregate pores, as suggested by some authors. Finally, the volume of pore water was found to agree closely with the volume of intra-aggregate pores, providing support to the assumption that in an unsaturated aggregate microstructure the clay aggregations are saturated.

KEYWORDS: compaction; laboratory tests; microscopy; partial saturation
L'influence de la composition sur le comportement mécanique est examinée de façon explicite dans certains modèles constitutifs de sols non saturés. Ces modèles sont fondés sur des hypothèses concernant l'interaction entre différents niveaux d'une structure, qui n'ont pas été validées par des expériences. On a effectué une étude pour examiner l'évolution de l'assemblage dans une argile naturelle, compactée au cours du mouillage et de la mise sous charge, dont les résultats sont présentés dans la présente communication. On a soumis des échantillons d'argile de Londres à un compactage statique dans les mêmes conditions initiales, à un assèchement de la teneur optimale en humidité dans une courbe de Proctor, puis à des chemins de contrainte complexes comportant le mouillage, la mise sous charge, ou une combinaison des deux. On a procédé à des analyses sur porosimètres par intrusion de mercure (MIP) et à des recherches de la microstructure par microscopie environnementale à scannage électronique (ESEM) pour observer et quantifier les changements survenus dans l'assemblage en ce qui concerne chaque chemin. On a observé le changement de l'assemblage du sol d'un agrégat à une structure de type matriciel le long de tous les chemins de mouillage, et on a relevé que cette transition ne se produisait que lorsque l'aspiration diminuait jusqu'à un niveau proche de zéro kPa. Les résultats ont également démontré que les variations de l'assemblage au cours de la déformation étaient tributaires du chemin de tension. II n'a pas été possible de déterminer un lien entre le volume de porosité libre et le volume de pores intra agrégats, avancé par certains auteurs. Enfin, on a établi que le volume d'eau interstitielle correspond de près au volume de pores intra agrégats, ce qui favorise l'hypothèse d'après laquelle, dans une microstructure d'agrégats non saturés, les agrégations d'argile sont saturées.

\section{INTRODUCTION}

A significant portion of our current understanding of the behaviour of unsaturated clays has been derived from tests carried out in the laboratory on compacted samples. A number of studies conducted in the early 1970s showed that soil compacted statically on the dry side of optimum in a Proctor plot tends to display a bimodal pore size distribution (Diamond, 1970; Sridharan et al., 1971; Ahmed et al., 1974; Garcia-Bengochea et al., 1979).

Several frameworks and constitutive models now available in the literature are capable of capturing some of the most important features of unsaturated soil behaviour. However,

Manuscript received 21 October 2008; revised manuscript accepted 27 April 2009. Published online ahead of print 18 December 2009. Discussion on this paper closes on 1 July 2010, for further details see p. ii.

* Georgia Institute of Technology, Atlanta, USA (Formerly Imperial College London, UK)

$\dagger$ Department of Civil and Environmental Engineering, Imperial College, London, UK

\$ Geotechnical Observations Ltd, Egham, Surrey, UK when it comes to modelling the particular, and complex, behaviour of clays, most do not explicitly consider the role of fabric or stress-strain history in their formulation. The Barcelona Expansive Model (BExM) (Gens \& Alonso, 1992; Alonso, 1998; Alonso et al., 1999) addresses the role of fabric on soil response, although the formulation is limited to the particular case of a double porosity structure, such as the one observed in samples compacted dry of optimum moisture content.

An extension of the original Barcelona Basic Model (BBM) (Alonso et al., 1987, 1990), the BExM explicitly considers two levels of structure: $(a)$ the microstructure, corresponding to the active clay minerals and their vicinity; and (b) a macrostructural level, which accounts for the large-scale structure of the soil. A certain degree of coupling between both levels of structure is included in the formulation. This is thought to be responsible for the build-up of irreversible macrostructural strains derived from the assumed reversible strains taking place at the microstructural level.

The ideas included in the BExM are interesting, as they provide a simple mechanism of visualising the mechanical response of an expansive soil consisting of aggregates, when 
subjected to changes in load and suction. As Lloret et al. (2003) point out, the model serves as a consistent tool to gain a better understanding of soil behaviour and the mechanisms that underlie it. However, at present, there is limited experimental evidence to support all of the ideas and assumptions included in this model, in particular with regards to the interaction between both levels of structure.

As part of a broader experimental programme looking at the mechanical response of compacted London Clay along complex stress paths (Monroy, 2006), a small study was carried out to evaluate the changes in fabric that took place along paths involving monotonic wetting and loading. Samples were statically compacted to the same initial conditions, corresponding to dry of optimum, and taken to a number of different final states. Microstructural investigations of the original and final fabrics were carried out using a mercury intrusion porosimeter (MIP) and an environmental scanning electron microscope (ESEM). Given that the initial fabric of the soil was observed to display the double porosity characteristic of clayey soils compacted under similar conditions, it was considered appropriate to select the BExM among the different available models for unsaturated soils to analyse and interpret the results of this study. The data presented in this paper combine the hydro-mechanical response of the soil with observations of micro- and macrostructural features. The results are used to compare assumptions regarding fabric evolution with actual soil response.

Small parts of this experimental study have been presented in Monroy et al. (2007b, 2008). This paper reproduces some of the figures to present the full experimental programme that provides an overall picture of the soil response, in which the different states (in terms of void ratio, net stress, degree of saturation and suction) are associated with the observed structural features and interpreted within known constitutive frameworks.

\section{MATERIALS AND METHODS}

Material properties and method of sample preparation

The soil selected for this study was weathered London Clay, obtained from a number of boreholes from a site in north London. In order to limit variability, only material from depths $4 \mathrm{~m}$ to $6 \mathrm{~m}$ was tested. The following properties were measured in the laboratory: liquid limit $w_{\mathrm{L}}=83 \%$, plasticity index $I_{\mathrm{P}}=54 \%$, specific gravity $G_{\mathrm{s}}=2 \cdot 70$, clay content of $58 \%$, and fines content (particles smaller that $0.06 \mathrm{~mm}$ ) of $98 \%$.

An evaluation of the mineralogical composition of the material was not carried out during the course of the present study. However, Gasparre (2005) performed X-ray analyses on samples of London Clay retrieved at the Heathrow Terminal 5 Site, in west London, and the results are presented in Table 1. These show London Clay to be rich in illite and smectite.

Prior to testing, the clay was dried at a temperature not exceeding $65-70^{\circ} \mathrm{C}$, before being mechanically ground into a fine powder. This was mixed with a given amount of water and the moist soil was left to hydrate for a minimum of 3 months inside sealed, air-tight bags.
Following hydration, the soil was statically compacted using a modified floating ring mould (Shackel, 1970; Colmenares-Montanez, 2002; Monroy, 2006) directly into the oedometer ring (final sample diameter of $75 \mathrm{~mm}$ and height of $30 \mathrm{~mm}$ ). Samples were compacted to the same initial conditions dry of optimum moisture content. A total of 83 samples were prepared and compacted following this method, of which eight were used to carry out the fabric studies (the remaining samples were used to evaluate the mechanical response along complex stress paths involving loading, unloading, wetting and drying). The as-compacted properties measured in all of the 83 samples are those summarised in Table 2.

\section{Stress paths}

Following compaction, samples were taken along various stress paths to different final states of applied stress and suction. Both conventional and osmotic oedometers were used during this stage. The osmotic oedometers allowed the independent measurement and control of the matric suction under atmospheric conditions (Dineen \& Burland, 1995; Monroy et al., 2007a). After reaching equilibrium at the desired state, samples were quickly unloaded and removed from the oedometer, sealed in air-tight bags, and allowed to equilibrate for a minimum period of one month.

\section{Microstructural investigations}

Two sets of small sub-samples, of only $1-2 \mathrm{~g}$ in weight, were taken from each of the compacted samples. One set was freeze-dried to remove all pore fluid and vapours whilst preserving the original fabric (Delage et al., 1982). This set was tested in the mercury intrusion porosimeter. The second set was used to carry out observations of microfabric using an environmental scanning electron microscope (ESEM). This equipment allows direct examination of soil samples at their natural moisture content and, therefore, no special sample pre-treatment is required.

The measurement of the pore size distribution in a soil by mercury intrusion is now well established, despite there being some difficulties in interpreting the raw data (Diamond, 1970; Sridharan et al., 1971). The technique has been used since the 1970s to investigate the fabric of compacted clays (Diamond, 1970; Sridharan et al., 1971; Ahmed et al., 1974; Garcia-Bengochea et al., 1979). It is

Table 2. Measured properties in the 83 compacted samples

\begin{tabular}{l|c|c}
\hline Property & Average & Standard deviation \\
\hline Water content: \% & $23 \cdot 61$ & 0.56 \\
Dry density: $\mathrm{Mg} / \mathrm{m}^{3}$ & $1 \cdot 384$ & $0 \cdot 008$ \\
Void ratio, $e_{\mathrm{o}}$ & 0.952 & $0 \cdot 011$ \\
Degree of saturation: \% & $67 \cdot 1$ & $1 \cdot 3$ \\
Matric suction: $\mathrm{kPa}^{*}$ & 996 & 103 \\
\hline
\end{tabular}

* Measured in 57 of the 83 samples using the IC tensiometer (Ridley \& Burland, 1995)

Table 1. X-ray analysis on samples of London Clay from different lithological units (after Gasparre, 2005)

\begin{tabular}{l|c|c|c|c|c|c|c}
\hline Unit & $\begin{array}{c}\text { Sample depth: } \\
\text { m }\end{array}$ & Illite: \% & $\begin{array}{c}\text { I-rich } \\
\text { illite-smectite: \% }\end{array}$ & $\begin{array}{c}\text { Random S-rich } \\
\text { illite-smectite: } \%\end{array}$ & Chlorite: \% & Kaolinite: \% & Clay: qtz \\
\hline C & 7 & 22 & 2 & 58 & 4 & 15 & $34 \cdot 0$ \\
B2 & 22 & 21 & 3 & 63 & 3 & 11 & $36 \cdot 8$ \\
A3 & 33 & 38 & 2 & 40 & 6 & 14 & $22 \cdot 4$ \\
\hline
\end{tabular}


based on the fact that mercury - a non-wetting fluid-needs to be pressurised in order for it to penetrate the soil (Diamond, 1970). An initially dry sample is placed inside the porosimeter and a vacuum is first applied. Mercury is then allowed into the chamber containing the sample and the pressure in the mercury is subsequently increased in steps. This causes the mercury to penetrate the voids progressively from the larger to the smaller, as the pressure is raised. The volume of mercury entering the sample during each pressure increment is continuously monitored.

The resistance to mercury penetration for the case of a cylindrical pore with a circular entrance is given by the Washburn equation (after Washburn, 1921)

$$
P_{\mathrm{Hg}}=-\frac{4 \sigma_{\mathrm{Hg}} \cos \theta_{\mathrm{nw}}}{x}
$$

where $P_{\mathrm{Hg}}$ is the absolute pressure required to force the mercury inside a pore of diameter $x, \sigma_{\mathrm{Hg}}$ is the surface tension of mercury, and $\theta_{\mathrm{nw}}$ denotes the contact angle between the mercury and the pore walls. In the present case, values of $\sigma_{\mathrm{Hg}}=0.484 \mathrm{~N} / \mathrm{m}$ (surface tension of mercury at $25^{\circ} \mathrm{C}$ ) and $\theta_{\mathrm{nw}}=140^{\circ}$ have been adopted. (Diamond (1970) measured the value of $\theta_{\mathrm{nw}}$ in clay and found this to correspond to $147^{\circ}$ for kaolinite and illite, and $139^{\circ}$ for the average of three montmorillonites. Subsequently, Delage \& Lefebvre (1984) adopted a value of $\theta_{\text {nw }}=141^{\circ}$ when testing natural clays. More recently, Romero (1999) used a value of $\theta_{\mathrm{nw}}=140^{\circ}$ for bentonite, and Delage et al. (2006) a value of $\theta_{\mathrm{nw}}=141.3^{\circ}$ when testing a sodium bentonite.)

The equipment used in this study, a Micromeritics-AutoProbe IV, allows application of absolute pressures to a maximum of $220 \mathrm{MPa}$. The range of pore diameters that can be intruded extends from approximately $400 \mu \mathrm{m}$ to $6.8 \mathrm{~nm}$ (68̊).

\section{MECHANICAL RESPONSE}

Before presenting the pore size distribution curves and ESEM images, the mechanical response of the material along the various stress paths is first introduced. This will allow better interpretation of the results within the doubleporosity BExM framework.

\section{The loading-collapse yield surface}

The BExM is formulated in terms of two independent stress variables, assumed to control the behaviour of unsaturated soils: the total net stress $p=\left(\sigma_{i j}-p_{\mathrm{a}} \delta_{i j}\right)$ and the matric suction $s=\left(p_{\mathrm{a}}-p_{\mathrm{w}}\right) \delta_{i j}$; where $\sigma_{i j}$ is the total stress, $p_{\mathrm{a}}$ and $p_{\mathrm{w}}$ the pore air and pore fluid pressures respectively, and $\delta_{i j}$ is the Kronechker's delta. In this paper, volume changes are related to variations of vertical net stress and matric suction. One of the central ingredients of the BExM framework consists of the locus of yield points in the $(p, s)$ space, assumed to separate reversible from irreversible responses. A stress path crossing this yield curve, either due to a reduction in suction or an increase in load, will result in irreversible volumetric strains. This is referred to as the loading-collapse (LC) yield curve, and the associated surface in the $e: p: s$ space, where $e$ represents the void ratio, is known as the LC yield surface (Alonso et al., 1987, 1990).

A number of tests were performed in the osmotic oedometer in order to locate the position of the LC yield surface (Monroy et al., 2008). Samples were wetted, either under a constant nominal vertical stress, or under conditions of zero volumetric strain, to different values of suction. This was followed by loading at constant suction beyond the yield stress.
Figure 1 shows the stress-strain response of three samples compacted to the reference initial state and allowed to hydrate to different final values of suction of 0,120 and $430 \mathrm{kPa}$, under a nominal vertical load of $7 \mathrm{kPa}$. As tests were carried out under atmospheric conditions, the vertical net stress is equivalent to the applied vertical stress. After reaching equilibrium, when no significant further changes in void ratio, suction, or degree of saturation were noticeable, the samples were loaded, and thereafter unloaded, at constant suction. The load was applied slowly and continuously, in order to ensure that the suction remained close to the equilibrium value (although no fixed rate of loading/unloading could be applied with the osmotic oedometer, this rate was adjusted automatically throughout a test, by a servocontrol system, to ensure that the suction in the soil, as measured with the IC tensiometer (Ridley \& Burland, 1995) at the top of the sample, was only a few $\mathrm{kPa}$ away from the equilibrium value at all times).

Figure 2 presents results from a second set of tests in which samples were hydrated at constant volume from the same reference state to similar values of suction as above (the maximum suction in this case was reduced from $430 \mathrm{kPa}$ to $405 \mathrm{kPa}$ ). As previously, after reaching equilibrium, the samples were loaded and unloaded at constant suction.

Figure 3 shows, in a single plot, the load-unload response of all six samples. It is apparent from this figure that, for a

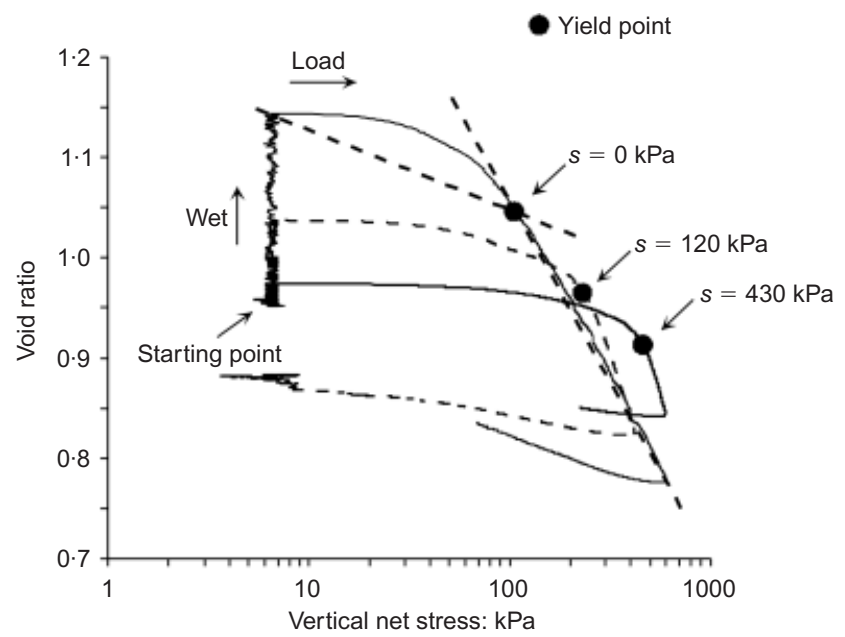

Fig. 1. Response of samples during wetting at nominal load followed by loading-unloading at constant suction

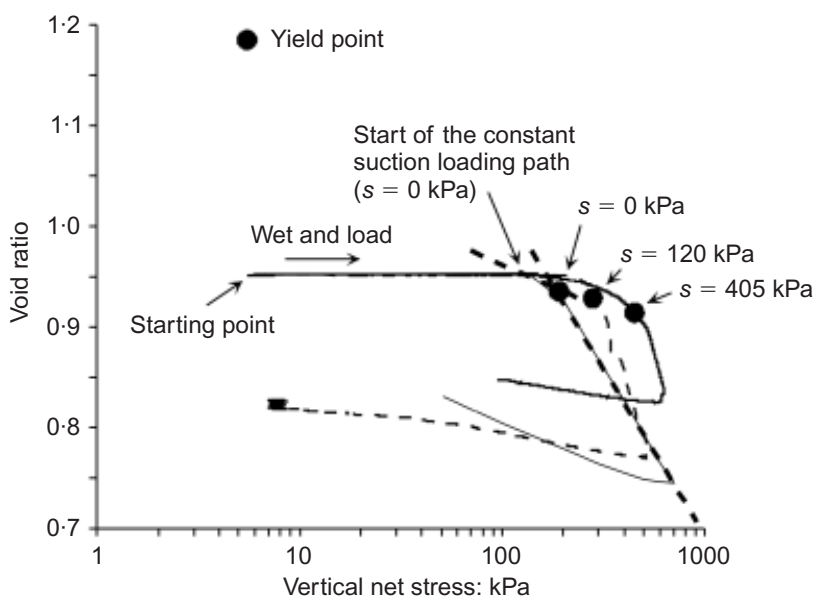

Fig. 2. Response of samples during wetting at constant volume followed by loading-unloading at constant suction 


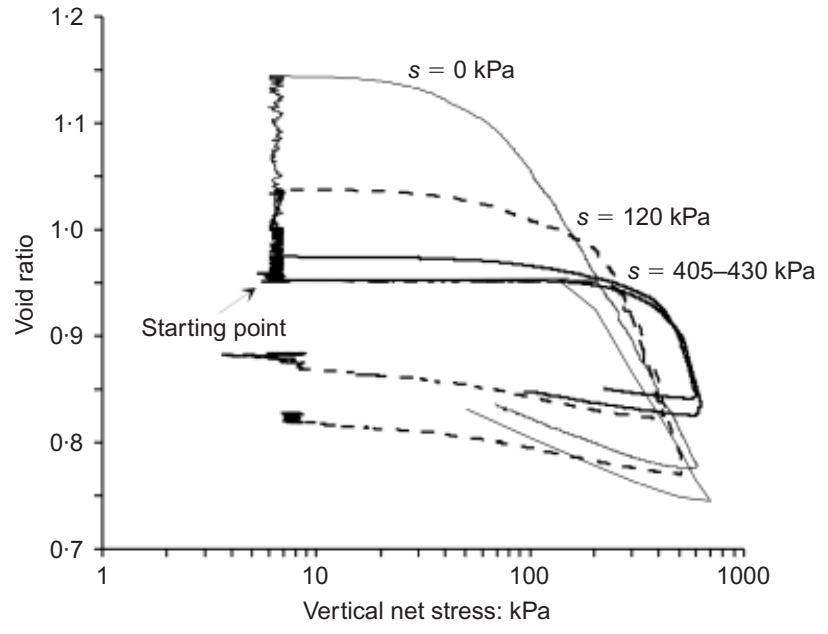

Fig. 3. Response of all samples loaded and unloaded at constant suction following different hydration paths

given value of suction, the stress path followed by samples hydrated to similar values of suction (free swell and confined wetting) has no effect on the subsequent response during loading beyond the yield point; that is, the normal compression line associated with a particular value of suction is stress path-independent for stress paths involving monotonic wetting prior to yielding.

The yield stress associated with each of the above two methods of hydration was defined in an arbitrary way, as the intersection between the normal compression line-assumed to be a straight line - and a second line drawn parallel to the swelling line for the particular value of suction, and having as origin the start of the loading path. The yield points thus obtained, marked in Figs 1 and 2 as black dots, have been plotted in Fig. 4. They can be seen to define two yield curves in the $p: s$ plane, each associated with a particular method of hydration (free swell and confined wetting). Both curves are located on the LC yield surface, although it is possible that neither of them corresponds to the LC yield curve. This is because in order to locate the LC yield curve, as defined in the BBM, it is necessary for the soil to undergo reversible straining during wetting. In the present

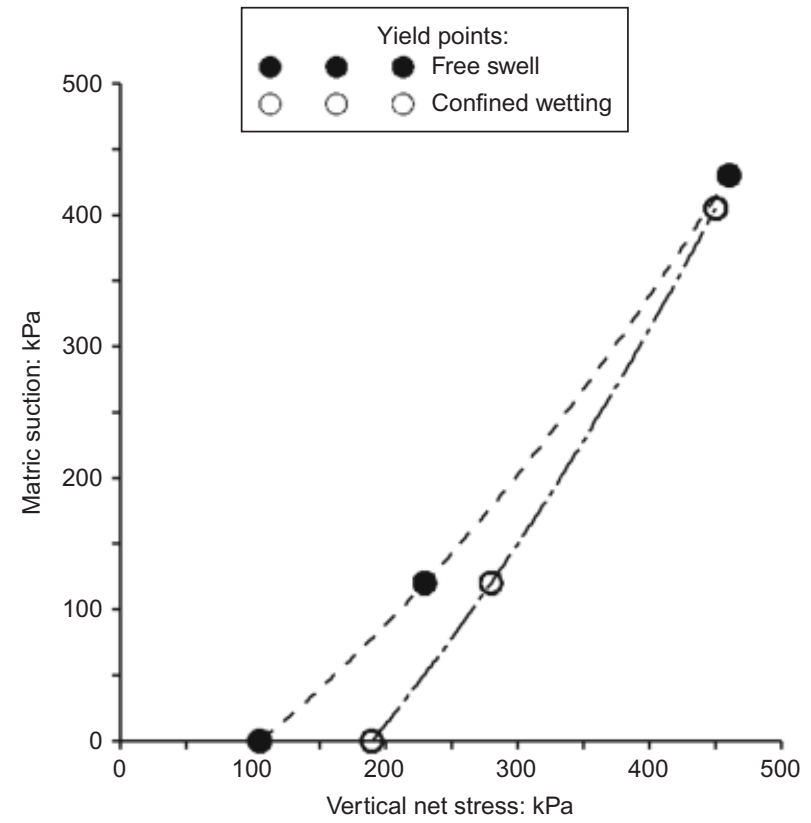

Fig. 4. Yield points associated with the two methods of hydration case, swelling under a nominal load might have had a significant component of irreversibility. Additionally, confined wetting prevented any sort of straining. Therefore, it might be reasonable to assume the LC yield curve to be located somewhere between the two yield lines presented in Fig. 4. However, it is acknowledged that a different interpretation is also possible and that, owing to their closeness, one might assume that both yield lines coincide and represent the LC yield curve. This would be appropriate for a situation in which wetting does not result in significant irreversible swelling.

Main assumptions of the double-structure BExM formulation

The BExM makes two fundamental assumptions regarding soil behaviour.

(a) Whatever the origin of the irreversible volumetric strains associated with the crossing of the LC yield curve, owing to either a decrease in suction or an increase in load, the effect on the structure of the soil will be similar.

(b) The magnitude of the irreversible macrostructural strains, $\mathrm{d} \varepsilon^{\mathrm{M}}$, during wetting is controlled by the degree of microstructural straining, $\mathrm{d} \varepsilon^{\mathrm{m}}$, the confining net stress at which wetting takes place, $p$, and the soil density.

Soil density is represented by the yield net stress, $p_{0}$, associated with the current value of suction: that is for a given fabric type and value of suction, a denser state of packing results in a higher value of yield stress. A soil wetted under a value of $p$ significantly lower than $p_{0}$ will experience, according to the formulation, large expansive micro- and macrostructural strains. As the value of $p$ at which wetting takes place is increased, both micro- and macrostrains will decrease in magnitude. A point will be reached in which the magnitude of the external load is high enough to cause the microstructural expansion to invade the macrostructural pore space. In this case, wetting will result in an increase in microporosity and a decrease in overall macroporosity. The relationship between $\mathrm{d} \varepsilon^{\mathrm{M}}$ and $\mathrm{d} \varepsilon^{\mathrm{m}}$ during wetting for different values of confining stress is given by a coupling function. This is represented in Fig. 5 by the curve labelled suction decrease. This can be seen to take large positive values at low ratios of $p / p_{\mathrm{o}}$ and to decrease steadily as this ratio increases, eventually becoming negative as $p / p_{0}$ approaches unity (micro- and macrostructural strains having different sign). An equivalent function is suggested for paths involving drying (represented by the suction increase curve shown in the same figure).

Selection of stress paths for microstructural investigations

The stress paths followed by the eight chosen compacted samples are presented in Fig. 6, together with the yield curves associated with free swell and confined wetting, previously introduced. In the figure, sample mta-1 represents the as-compacted condition.

Three initial stress paths were selected for samples mta-2, mta- 3 and mta- 6 as follows.

(a) Sample mta-2 was wetted under a nominal vertical load of $7 \mathrm{kPa}$ and was allowed to reach equilibrium under a suction of $0 \mathrm{kPa}$. This would correspond to a condition where the value of $p / p_{0}$ is very low.

(b) Sample mta-3 was loaded at constant moisture content to a maximum vertical net stress of $550 \mathrm{kPa}$. At this level of stress it is believed that the stress path had just reached the LC yield surface. Fig. 7 shows volumetric 


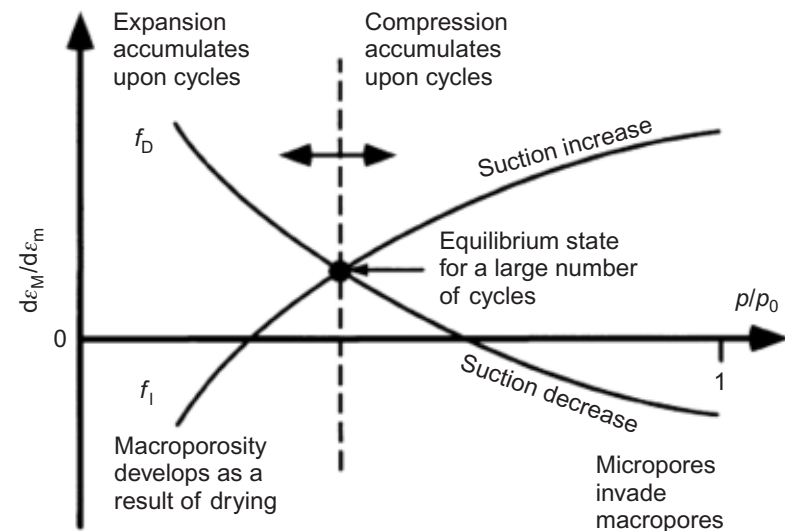

Fig. 5. Shape of coupling functions (Alonso et al., 1999)

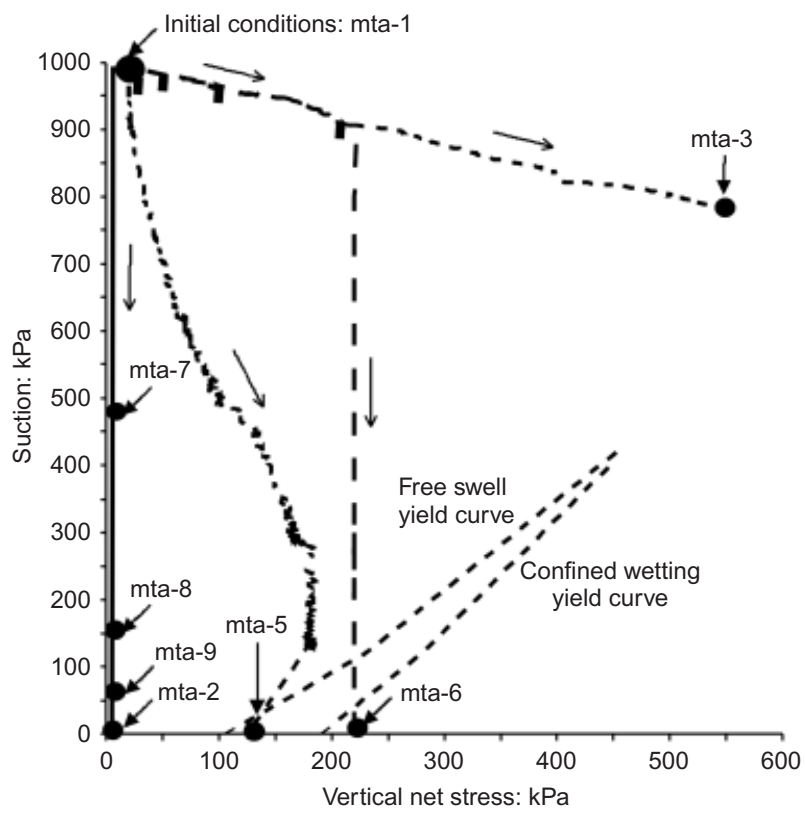

Fig. 6. Stress paths followed by the eight compacted samples

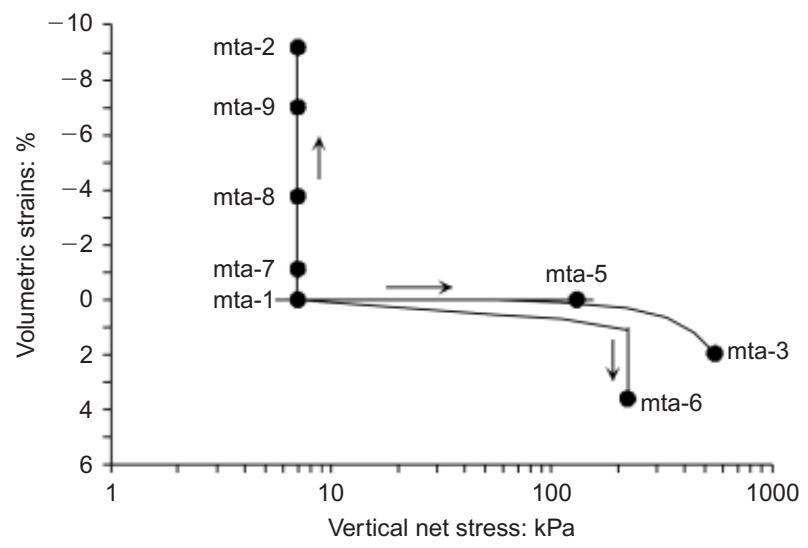

Fig. 7. Stress-strain response of the eight compacted samples during loading and wetting

strains plotted against vertical net stress. It is possible to see from this figure how mta-3 underwent some degree of yielding at the end of the stress path. During loading, which was carried out in steps, the suction in the soil was observed to decrease uniformly, as shown in Fig. 6, and to attain a final value of approximately $780 \mathrm{kPa}$. Although it has been previously reported in the literature that samples compacted on the dry side of optimum moisture content tend to display values of suction independent of density (Delage \& Graham, 1995; Romero et al., 1999), the degree of saturation in the present case might have been sufficiently high, and the clay aggregates sufficiently deformable, for compression to have an effect on suction. The variations in void ratio and degree of saturation with load are plotted in Fig. 8.

(c) Sample mta-6 was loaded at constant moisture content to a vertical stress of $220 \mathrm{kPa}$. Thereafter, wetting took place under constant load. Fig. 6 shows how the wetting path crossed both yield curves (and therefore reached the LC yield surface). This is confirmed in Fig. 7, which shows the sample to have undergone some nominal swelling before collapsing to the final state (although minimal, this swelling can be identified as the portion of the vertical line representing volume collapse protruding above the end of the loading path). Wetting of sample mta- 6 took place at an intermediate value of $p / p_{0}$. The final vertical strains measured in samples mta-6 and mta-3 are different (Fig. 7); however, their void ratios are very similar, 0.898 and 0.908 respectively, due to small differences in initial void ratio. Therefore, although being at different final states in the $p: s$ plane, the state of both samples with regards to void ratio can be considered to be almost identical. As the final states of both mta- 6 and mta- 3 can be assumed to be located in the LC yield surface, comparison of final fabric displayed by both samples should serve to verify the first assumption mentioned above, which states that irreversible volumetric strains associated with yielding along the LC yield surface result in similar effects on the structure of the soil.

To further investigate the effect of hydration path on microstructural changes, an additional sample, mta-5, was wetted under a condition of zero volumetric strain. The path followed by a sample hydrated under these conditions is shown in Fig. 6. As suction is decreased, the vertical stress needed to be increased at first; however, as the LC yield surface was approached, the sample displayed a tendency to collapse, thus requiring a reduction in vertical stress.

Besides looking at the fabric corresponding to the final state along a particular stress path, it was thought interesting to trace the evolution of the microstructure along such paths. Ideally, paths followed by samples mta-2, mta-5 and mta-

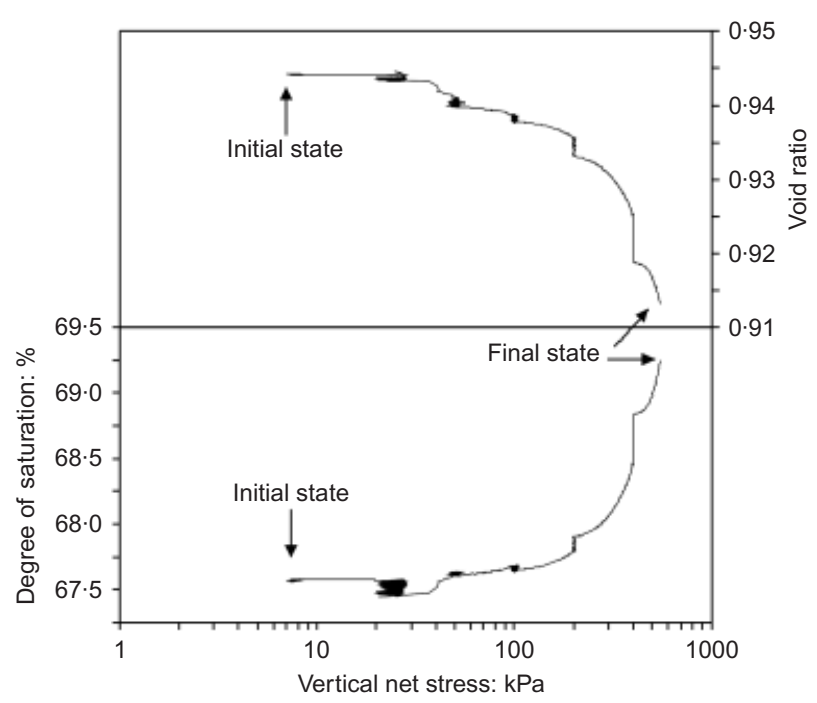

Fig. 8. Variation of void ratio and degree of saturation in sample mta-3 during loading at constant moisture content 
6-all of which underwent a reduction in suction-would have been investigated. However, during the course of the present investigation it was only possible to carry out this additional exercise along the path followed by sample mta-2 (wetted under a nominal load of $7 \mathrm{kPa}$ ).

Samples mta-7, mta- 8 and mta-9 were all hydrated under a vertical load of $7 \mathrm{kPa}$ and allowed to come to equilibrium at suctions of approximately $470 \mathrm{kPa}, 150 \mathrm{kPa}$ and $40 \mathrm{kPa}$ respectively (see Figs 6 and 7). The response of these three samples, together with that of sample mta-2, along the hydration path is shown in Fig. 9 in terms of void ratio, degree of saturation, and volume of void space occupied by water, $e_{\mathrm{w}}$. This last quantity corresponds to the specific

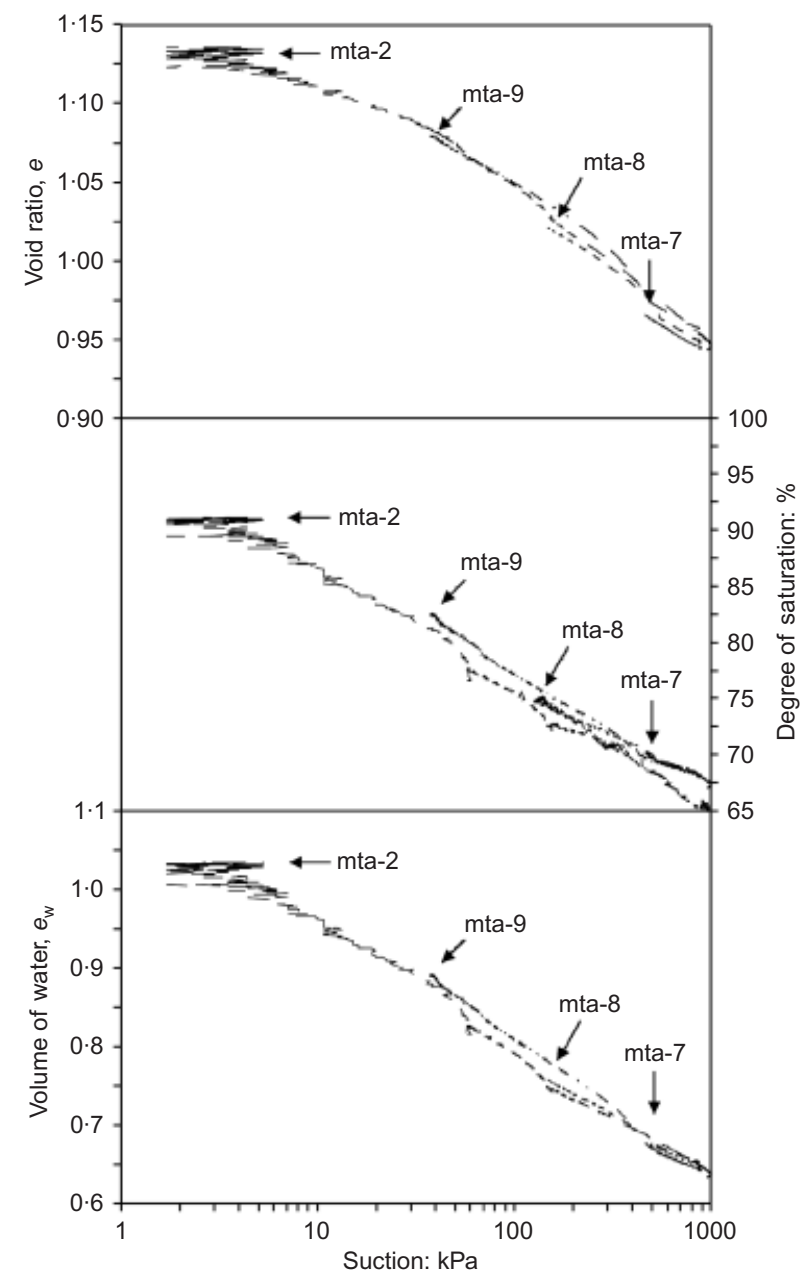

Fig. 9. Variation in void ratio, degree of saturation and volume of water during hydration under a nominal load at $7 \mathrm{kPa}$ water volume (Wheeler, 1991) minus the volume of solid particles:

$$
\begin{aligned}
& e_{\mathrm{w}}=v_{\mathrm{w}}-1=\left(e S_{\mathrm{r}}+1\right)-1=\left(w G_{\mathrm{s}}+1\right)-1 \\
& e_{\mathrm{w}}=e S_{\mathrm{r}}=w G_{\mathrm{s}}
\end{aligned}
$$

Figure 9 shows all samples to display similar response (although this is expected, a deviation from this result would cast doubts over the consistency and validity of the microstructural analyses presented in this paper). It is interesting to note that the final degree of saturation for sample mta-2 is approximately $91 \%$. This result was confirmed by a number of additional tests carried out under similar conditions. Samples mta-5 and mta-6, on the other hand, attained values of $S_{\mathrm{r}}$ close to $100 \%$ at the end of the hydration stage. Unfortunately, the response of these two samples was not monitored continuously during wetting and similar results to those shown in Fig. 9 are not available.

In addition to the above, two more samples were prepared and tested: one corresponding to the initial as-compacted state, mta-1; and another, mta-10, obtained by consolidating reconstituted material (mixed at 1.5 times the liquid limit) one-dimensionally to a maximum vertical stress of $108 \mathrm{kPa}$ using a standard oedometer frame. Under a load of $108 \mathrm{kPa}$, mta-10 displayed a void ratio close to that attained by sample mta-2 when fully hydrated, 1.175 and 1.142 respectively, although the degrees of saturation are different in both cases.

A summary of measured values of $e, S_{\mathrm{r}}, s$, and $e_{\mathrm{w}}$ at the end of each of the loading and wetting paths is presented in Table 3. The suction in sample mta-1 was not measured and the number included in the table represents the average suction measured in all samples after compaction. The values in the table represent the state of the samples before being unloaded and removed from the oedometer.

\section{MERCURY INTRUSION POROSIMETRY INVESTIGATIONS \\ Clay microstructural levels}

Before presenting the results from the mercury intrusion porosimetry investigations and analysing the associated pore size distribution curves, the different clay microstructural levels considered in this study are first presented. The description is based on that given by Delage et al. (2006), where a summary of clay microstructural levels is presented based on a survey of observations carried out and reported in the literature over the years.

In a clay compacted on the dry side of optimum moisture content, clay particles - composed of face-to-face stacks of

Table 3. Measured properties of samples prior to removal from the oedometer

\begin{tabular}{l|c|c|c|c}
\hline Sample & Void ratio, $e_{\mathrm{o}}$ & Suction: $\mathrm{kPa}$ & $\begin{array}{c}\text { Degree of } \\
\text { saturation: } \%\end{array}$ & $\begin{array}{c}\text { Volume of water } \\
\text { in voids: } e_{\mathrm{w}}\end{array}$ \\
\hline mta-1 & 0.961 & $996^{*}$ & 66 & 0.632 \\
mta-2 & $1 \cdot 142$ & 0 & 91 & $1 \cdot 040$ \\
mta-3 & 0.908 & 786 & 69 & 0.627 \\
mta-5 & 0.949 & 0 & 98 & 0.935 \\
mta-6 & 0.898 & 0 & 99 & 0.885 \\
mta-7 & 0.965 & 470 & 70 & 0.676 \\
mta-8 & 1.021 & 150 & 74 & 0.756 \\
mta-9 & 1.080 & 40 & 82 & 0.891 \\
mta-10 & 1.175 & 0 & 100 & 1.175 \\
\hline
\end{tabular}

\footnotetext{
* The suction in sample mta-1 was not measured: the value reported corresponds to the
} average suction given in Table 2 
unit clay layers - come together to form aggregates. Within this structure, one can identify various levels of porosity

(a) planar inter-layer pore space between the individual unit clay layers within the clay particles, known as the inter-layer or intra-particle porosity

(b) voids between the individual particles within the aggregates, referred to as the inter-particle porosity or intra-aggregate porosity

(c) large voids between the aggregates of clay particles, referred to as inter-aggregate porosity.

Saiyouri et al. (1998, 2000, 2004) carried out tests on two heavily compacted smectites (FoCa clay and MX80 clay) and suggested that hydration is governed by the progressive inclusion of layers of water molecules along the surface of the unit clay layers within the clay particle. The number of layers of water molecules was reported to vary from zero in the dry state (equivalent to an inter-layer separation of $0.4 \AA$ ) to a maximum of four in the fully hydrated state (corresponding to an inter-layer separation of $12 \AA$ ). Separations larger than $12 \AA$ were interpreted to correspond to interparticle distances.

In the present study the minimum pore diameter which could be intruded with the equipment was $6.8 \mathrm{~nm}(68 \AA)$; therefore, the very small inter-particle porosity between $12 \AA$ and $68 \AA$ would have remained undetected. Following the terminology employed by Delage et al. (2006), the term 'very thin porosity' will be used to refer to the inter-particle pore space not intruded by mercury and corresponding to an equivalent entrance diameter smaller than $6.8 \mathrm{~nm}$.

\section{Initial as-compacted state}

Figure 10 shows the pore size distribution curve of sample mta-1, corresponding to the initial as-compacted state. Curves are presented in terms of both cumulative and density functions in semi-logarithmic graphs, with the equivalent entrance pore diameter, calculated with equation (1), plotted on the abscissa. The cumulative curve is presented in terms of the intruded mercury void ratio, $e_{\mathrm{nw}}$ (volume of non-wetting fluid divided by volume of solid particles). The figure also shows the total void ratio measured in the sample at the end of the compaction process, $e_{0}$. A continuous intrusion curve is obtained by joining the 130 experimental points monitored during the test. For clarity,

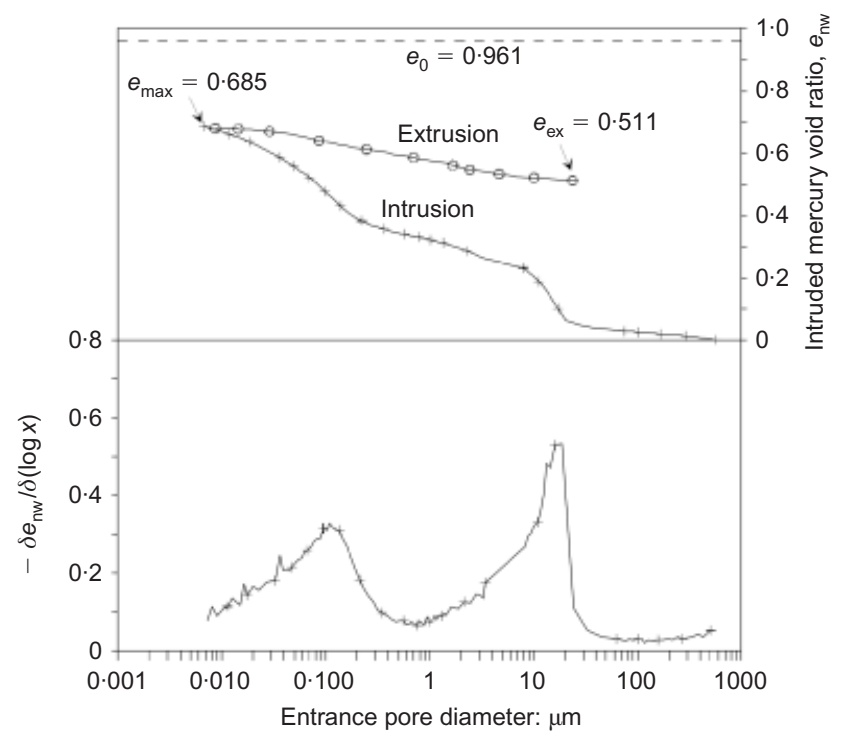

Fig. 10. Pore size distribution and density function for sample mta-1 however, only a few of these points are represented with a symbol.

Observation of Fig. 10 reveals a significant difference between the sample's measured void ratio at the end of compaction, $e_{0}$, and the total intruded volume of mercury, $e_{\max }$, in the order of $0 \cdot 276$. This is common when carrying out porosimetry studies, and in the present case can be attributed to two main reasons

(a) pores that have sizes too small to be intruded with the available equipment (non-intruded porosity) will remain undetected

(b) pores that are isolated by surrounding solid particles (enclosed porosity) will not be measured.

It is also possible that pores in a sample are too large to be detected with the minimal pressure the equipment is able to deliver (non-detected porosity). However, in the present case the volume of non-detected porosity was measured to be close to zero, a shown in Fig. 10.

In compacted clays, the effect of enclosed porosity is believed to be of less significance than that of non-intruded porosity (Simms \& Yanful, 2004). Therefore, in this study it is assumed that the difference $e_{0}-e_{\max }$ reflects the volume of non-intruded porosity with an equivalent entrance diameter smaller than $6 \cdot 8 \mathrm{~nm}$, corresponding to the very thin porosity defined above.

At the end of the first intrusion cycle, the pressure was released and the mercury allowed to exit the sample. This resulted in the extrusion curve shown in Fig. 10. The initial intrusion cycle can be thought to have filled all the accessible and interconnected pore space, giving the distribution of total porosity; whereas on complete release of the intrusion pressure, only some of the mercury filling the nonconstricted pores would have exit the sample (Delage \& Lefebvre, 1984). Constricted porosity would then refer to pores that are accessible only through smaller ones and are not detected until the small pore is penetrated. It has been found experimentally that a second intrusion curve follows approximately the extrusion path, thus defining the free porosity (Delage \& Lefebvre, 1984). Therefore, the difference between the intrusion and extrusion cycles gives a measure of the entrapped porosity. In this study, the volume of mercury remaining in the sample after the release of pressure has been denoted as $e_{\mathrm{ex}}$ (see Fig. 10).

According to the above, three types of porosity can be defined in Fig. 10

(a) non-intruded porosity, corresponding to the difference $e_{\mathrm{o}}-e_{\max }$

(b) free porosity, corresponding to the difference $e_{\max }-e_{\mathrm{ex}}$

(c) entrapped porosity, corresponding to the difference $e_{\mathrm{ex}}$ - $e_{\min }$ (however, since $e_{\min }$ was found to be close to zero in all cases, the value of entrapped porosity is equivalent to $e_{\mathrm{ex}}$ ).

Numerical values for each of the above, as measured in each of the samples, are presented in Table 4.

The derivative of the cumulative intrusion curve gives the pore size density function shown on the lower part of Fig. 10 (Juang \& Holtz, 1986a). This function, defined as

$$
f\left(\log x_{\mathrm{m}}\right)=-\frac{\delta e_{\mathrm{nw}}}{\delta(\log x)}
$$

that is the change in intruded void ration, $\delta e_{\mathrm{nw}}$, divided by the change of the logarithm of two adjacent apparent entrance pore diameters, as reported by the equipment, $\delta(\log$ $x$ ), is evaluated at the mid-point, $\log x_{\mathrm{m}}$, of each class width $\delta(\log x)$. The ordinate in the bottom part of Fig. 10 therefore corresponds to $x_{\mathrm{m}}$ and not $x$ as shown. However, the 
Table 4. Volumes of non-detected, free and entrapped porosities

\begin{tabular}{|c|c|c|c|c|c|}
\hline Sample & Initial void ratio, $e_{\mathrm{o}}$ & $\begin{array}{l}\text { Max. intruded porosity, } \\
e_{\max }\end{array}$ & $\begin{array}{l}\text { Non-detected porosity, } \\
\qquad\left(e_{\mathrm{o}}-e_{\max }\right)\end{array}$ & $\begin{array}{l}\text { Free porosity, } \\
\qquad\left(e_{\max }-e_{\mathrm{ex}}\right)\end{array}$ & $\begin{array}{c}\text { Entrapped porosity, } \\
e_{\mathrm{ex}}\end{array}$ \\
\hline $\begin{array}{l}\text { mta-1 } \\
\text { mta-2 } \\
\text { mta-3 } \\
\text { mta-5 } \\
\text { mta-6 } \\
\text { mta-7 } \\
\text { mta-8 } \\
\text { mta-9 } \\
\text { mta-10 }\end{array}$ & $\begin{array}{l}0 \cdot 961 \\
1 \cdot 142 \\
0 \cdot 908 \\
0 \cdot 949 \\
0 \cdot 898 \\
0 \cdot 965 \\
1 \cdot 021 \\
1 \cdot 080 \\
1 \cdot 175\end{array}$ & $\begin{array}{l}0 \cdot 685 \\
0 \cdot 933 \\
0 \cdot 708 \\
0 \cdot 799 \\
0 \cdot 701 \\
0 \cdot 72 \\
0 \cdot 711 \\
0 \cdot 823 \\
0 \cdot 976\end{array}$ & $\begin{array}{l}0 \cdot 276 \\
0 \cdot 209 \\
0 \cdot 200 \\
0 \cdot 150 \\
0 \cdot 197 \\
0 \cdot 245 \\
0 \cdot 310 \\
0 \cdot 257 \\
0 \cdot 199\end{array}$ & $\begin{array}{l}0 \cdot 174 \\
0 \cdot 162 \\
0 \cdot 182 \\
0 \cdot 168 \\
0 \cdot 173 \\
0 \cdot 188 \\
0 \cdot 172 \\
0 \cdot 165 \\
0 \cdot 137\end{array}$ & $\begin{array}{l}0.511 \\
0.771 \\
0.526 \\
0.631 \\
0.528 \\
0.532 \\
0.539 \\
0.658 \\
0.839\end{array}$ \\
\hline
\end{tabular}

difference between these two diameters is minimal and therefore, to simplify the figure, only the equivalent entrance diameter $x$ has been plotted.

Figure 10 reveals a typical bimodal porosity for mta-1, indicative of an aggregate structure typical of a clayey soil compacted on the dry side of optimum. Two dominant pore groups can be identified, with entrance diameters grouped around $17 \cdot 440 \mu \mathrm{m}$ and $0 \cdot 110 \mu \mathrm{m}$. The larger pore size can be interpreted to correspond to the inter-aggregate pores and the smaller to the intra-aggregate pores.

\section{Effect of reaching the LC yield surface}

The pore size distribution curves of samples mta-3 (loaded at constant moisture content to $550 \mathrm{kPa}$ ) and mta-6 (loaded at constant moisture content to $220 \mathrm{kPa}$ followed by wetting at constant stress) are shown in Fig. 11. Both samples are assumed to have reached the LC yield surface. The final void ratios were found to be very similar $(0.908$ and 0.898 respectively). The top part of the figure shows the final volumes of intruded mercury to have been very similar as well $(0.708$ and 0.701 respectively), as were the volumes of very thin porosity $(\approx 0 \cdot 2)$. However, the bottom part of Fig. 11 shows clear differences in the distribution of the intruded pore space. Whereas mta-3 retained its original bimodal porosity induced by the preparation and compaction process, the pore space in mta- 6 is dominated by a single pore size, with entrance diameter of approximately $0.670 \mu \mathrm{m}$. Therefore, although both samples reached the LC

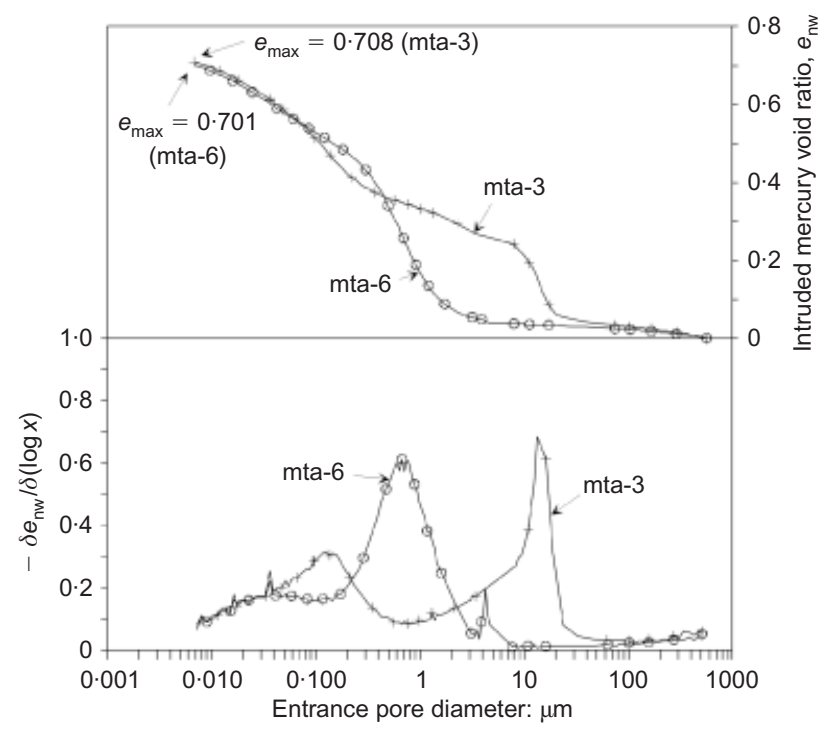

Fig. 11. Pore size distribution and density function for samples mta-3 and mta-6 yield surface and had similar void ratios, their different stress paths had a profound effect on the final fabric. It is interesting to note that the two cumulative and density curves are similar below an entrance diameter of $0.04 \mu \mathrm{m}$.

As shown in Fig. 12, the pore size distributions of samples mta-1 and mta-3 are very similar. It is possible to observe a slight reduction in the size of the dominant interaggregate pore size in mta-3 with respect to mta-1, from approximately $17.40 \mu \mathrm{m}$ to $14.730 \mu \mathrm{m}$. However, the distribution of the intra-aggregate porosity remains very similar. Although the final void ratios of mta-1 and mta-3 are 0.961 and 0.908 respectively, the total volume of intruded mercury is slightly greater for the second sample (resulting in a reduction in the calculated volume of very thin porosity from $0 \cdot 276$ and $0 \cdot 200$, as shown in Table 4). It is believed, however, that this might be attributable to experimental errors and variability between samples, rather than to the effect of loading. In fact, one would expect loading to have reduced the inter-aggregate porosity, as reported in the literature (Sridharan et al., 1971; Garcia-Bengochea et al., 1979; Delage \& Lefebvre, 1984; Juang \& Holtz, 1986b), and hence the volume of intruded mercury. It appears that in the present case, the maximum applied stress was too low to have any significant effect on the measured porosity.

\section{Effect of hydration path}

The pore size distribution curves of samples mta-2 (free swell) and mta-5 (confined wetting) are compared in Fig. 13.

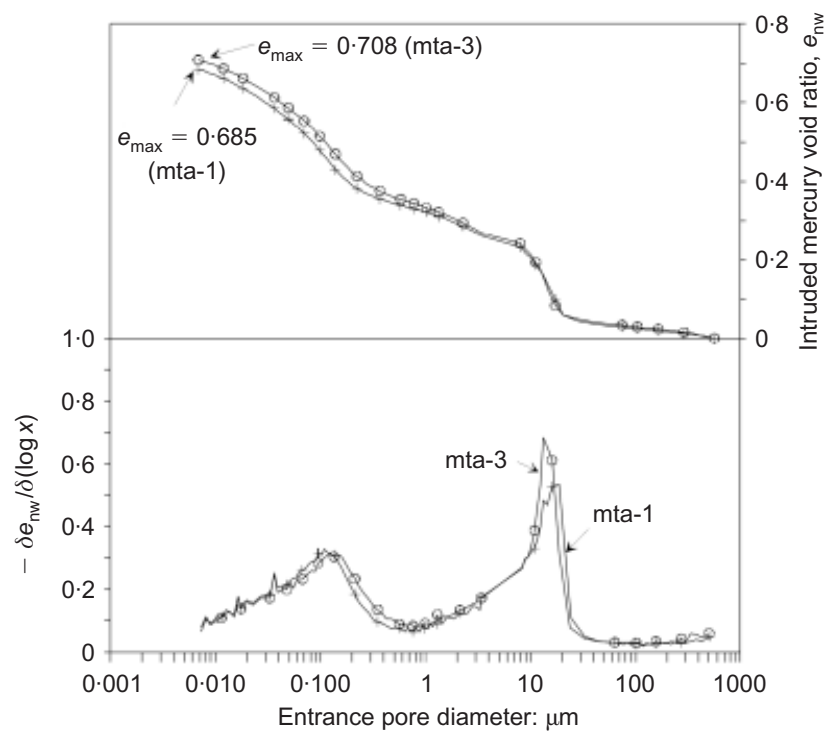

Fig. 12. Pore size distribution and density function for samples mta-1 and mta-3 


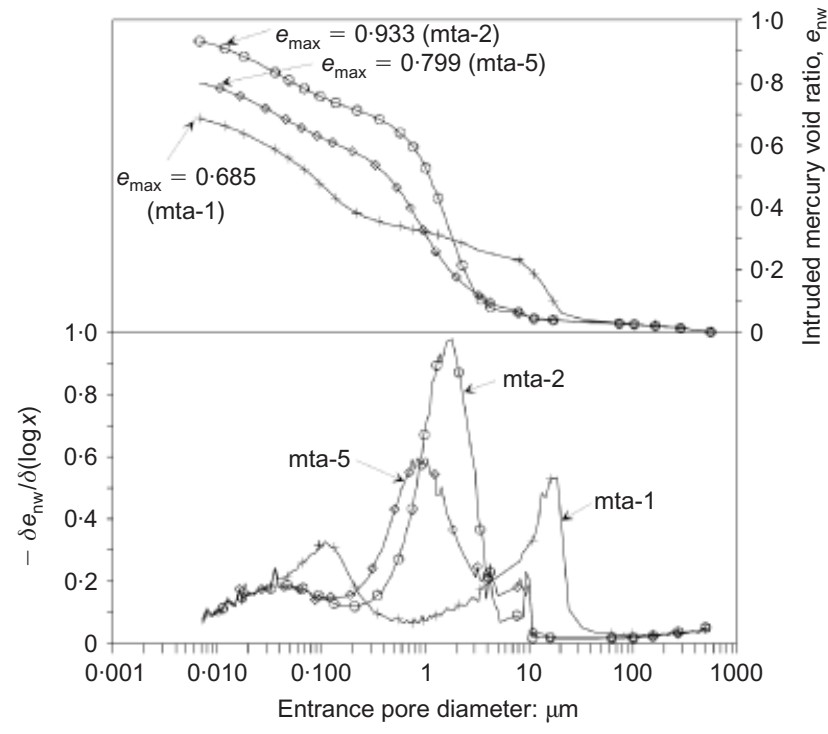

Fig. 13. Pore size distribution and density function for samples mta-1, mta-2 and mta-5

The same figure also includes the curve of sample mta- 1 for reference. Hydration resulted in a microfabric dominated by a single pore size, which for mta-2 was centred at an entrance diameter of around $1.730 \mu \mathrm{m}$, and for mta-5 at around $0.840 \mu \mathrm{m}$. With regards to the mechanical response of these two samples, it should be noted that $(a)$ the path followed by mta-2 was located away from the LC yield surface, whereas that of mta-5 was very close to this surface at low values of suction; and $(b)$ the equilibrium degrees of saturation of samples mta- 2 and mta-5 were $91 \%$ and $98 \%$ respectively.

The MIP results for all three fully hydrated samples, mta2, mta-5 and mta-6, are shown together in Fig. 14. All three samples can be seen to display a similar type of microstructure, dominated by a single pore entrance diameter, which reduces in size with an increase in vertical load (and a corresponding reduction in overall void ratio). It is interesting to note that all pore size density functions and cumulative pore size distributions are similar for pore sizes smaller than $0 \cdot 1 \mu \mathrm{m}$.

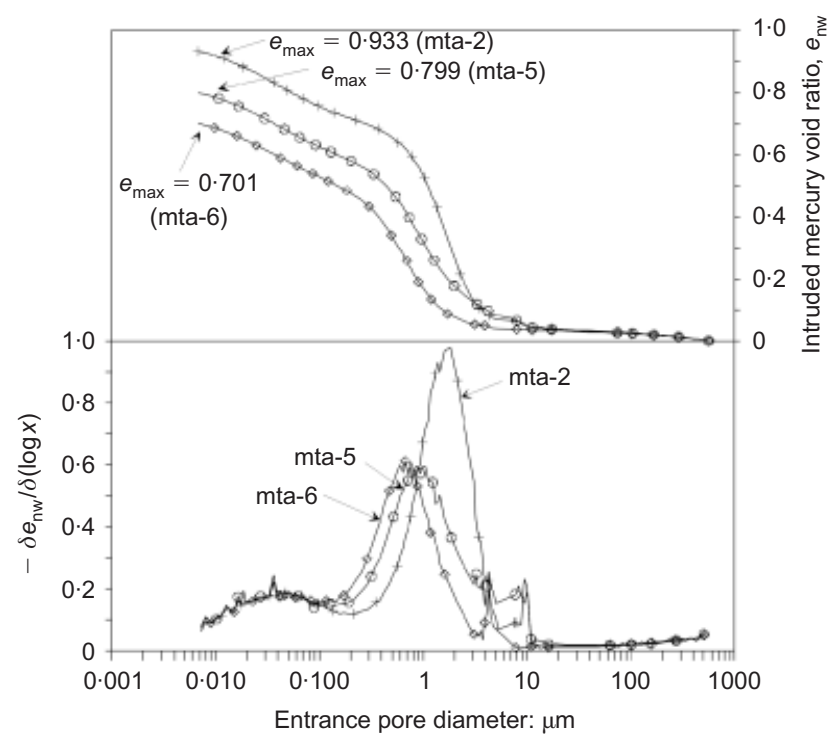

Fig. 14. Pore size distribution and density function for samples mta-2, mta-5 and mta-6
The results presented in Fig. 14 contrast with those presented in Thom et al. (2007), where it is shown that wetting of compacted kaolin does not erase the initial bimodal pore size distribution set up by the compaction process.

Microstructural changes along a wetting path

The pore size distributions obtained during different stages of hydration along a wetting path under a nominal load of $7 \mathrm{kPa}$ (mta-7, mta-8, mta-9) are shown in Fig. 15, together with the results for mta-2 (full hydration) and mta-1 (ascompacted). The associated volumetric strains and changes in degree of saturation are those presented in Figs 7 and 9. Fig. 15 shows how a reduction in suction from the original value of approximately $1000 \mathrm{kPa}$ to $40 \mathrm{kPa}$ causes the size of the dominant inter-aggregate pore entrance diameter to reduce from 17.440 to $11.680 \mu \mathrm{m}$, while that of the intraaggregate pore space increases from $0 \cdot 110$ to $0.470 \mu \mathrm{m}$. However, even at a low value of suction of $40 \mathrm{kPa}$, corresponding to $S_{\mathrm{r}}=82.5 \%$, there is still a clearly defined bimodal pore size distribution. It is the final reduction in suction from $40 \mathrm{kPa}$ to $0 \mathrm{kPa}$ which causes the important change in microfabric. It must be noted that the pore size density functions and cumulative pore size distributions are similar for pore sizes smaller than $0.04 \mu \mathrm{m}$.

Differences between a compacted and reconstituted soil

Finally, the pore size distributions of the compacted sample mta-2 and the reconstituted sample mta-10, both having similar void ratios (1.142 and 1.175 respectively) are compared in Fig. 16. As previously mentioned, sample mta10 had been one-dimensionally consolidated from a slurry to a maximum vertical stress of $108 \mathrm{kPa}$ in a standard oedometer. Both samples displayed a single dominant pore size, which appears to be characteristic of this material when in the fully hydrated state. However, the similarity in the pore size density functions and cumulative pore size distributions for entrance diameters smaller that $0.04 \mu \mathrm{m}$ or $0.1 \mu \mathrm{m}$ is not observed in this case. Additionally, the pore space in mta-10 seems to be more homogeneous, with most pores closely gathered around an entrance diameter of $0.670 \mu \mathrm{m}$, although there is also a significant proportion of porosity smaller than $0 \cdot 1 \mu \mathrm{m}$.

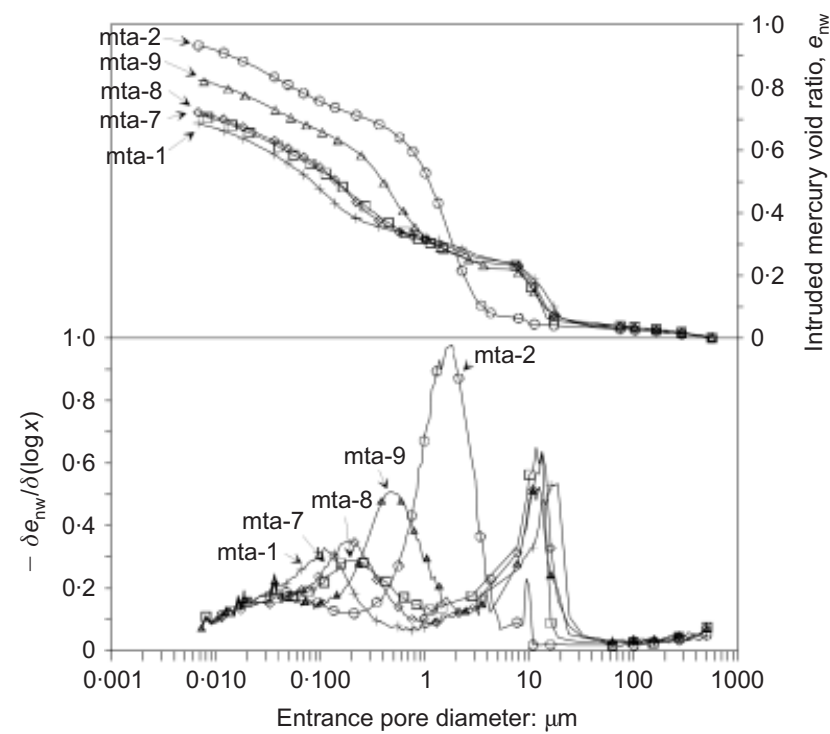

Fig. 15. Pore size distribution and density function for samples mta-1, mta-2, mta-7, mta-8 and mta-9 


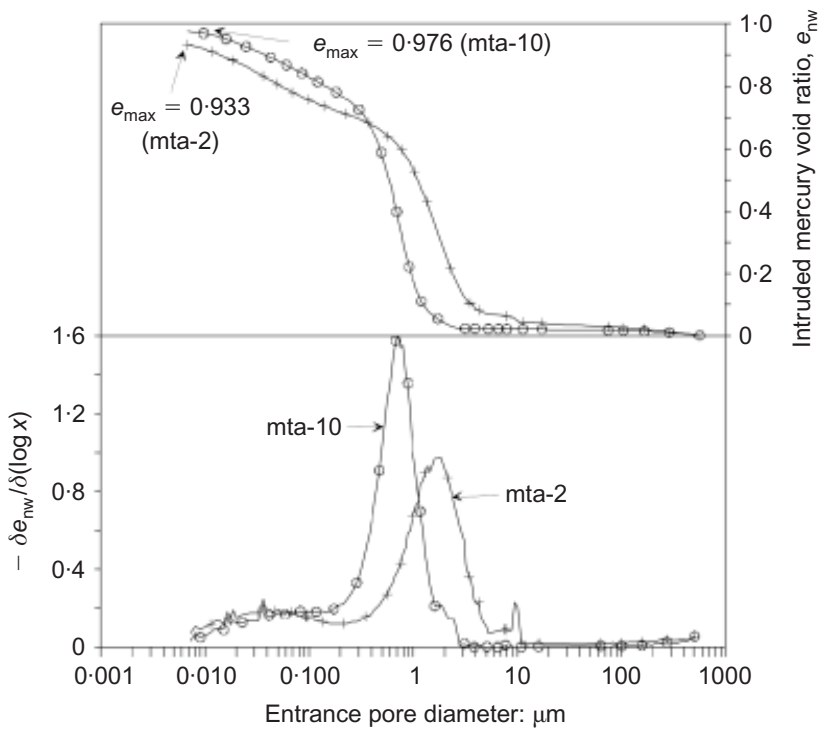

Fig. 16. Pore size distribution and density function for samples mta-2 and mta-10

\section{Distribution of pore space}

Although comparison of pore size density functions gives an insight into the evolution of dominant pore sizes, it gives no indication of relative volumes associated with the different pores. This information is contained in the cumulative pore size distribution curves. However, in their standard form, visual comparisons are difficult to make. In this section, the pore space is divided into discrete categories, associated with different sizes, in an attempt to quantify the variations in volume within each of these categories associated with the process of wetting and loading.

Volumes of very thin, or non-intruded, porosity $\left(e_{0}-e_{\max }\right.$, corresponding to pore entrance diameters smaller than $6 \cdot 8 \mathrm{~nm}$ ) range from $0 \cdot 31$ (mta-8) to $0 \cdot 15$ (mta-5), as reported in Table 4. Given that values of $e_{\mathrm{o}}$ were measured while samples were still in the oedometer, the estimates of very thin porosity cannot be considered to be reliable. Therefore, no further comments can be made regarding the distribution of pore diameters below the minimum value measured with the MIP.

Volumes of intruded mercury corresponding to equivalent entrance diameters between $6.8 \mathrm{~nm}$ and $0.04 \mu \mathrm{m}(40 \mathrm{~nm})$ are shown in Fig. 17. As pointed out earlier, the pore size distribution and pore size density functions for all compacted samples were observed to be similar below an entrance diameter of $40 \mathrm{~nm}$. Volumes of this porosity vary from 0.099 (mta-7) to $0 \cdot 108$ (mta-1 and mta-2), suggesting that hydration and loading had no significant effect on the pore space below this entrance diameter. This result also suggests that the very thin porosity with entrance diameter below $6.8 \mathrm{~nm}$ might have remained largely unchanged during
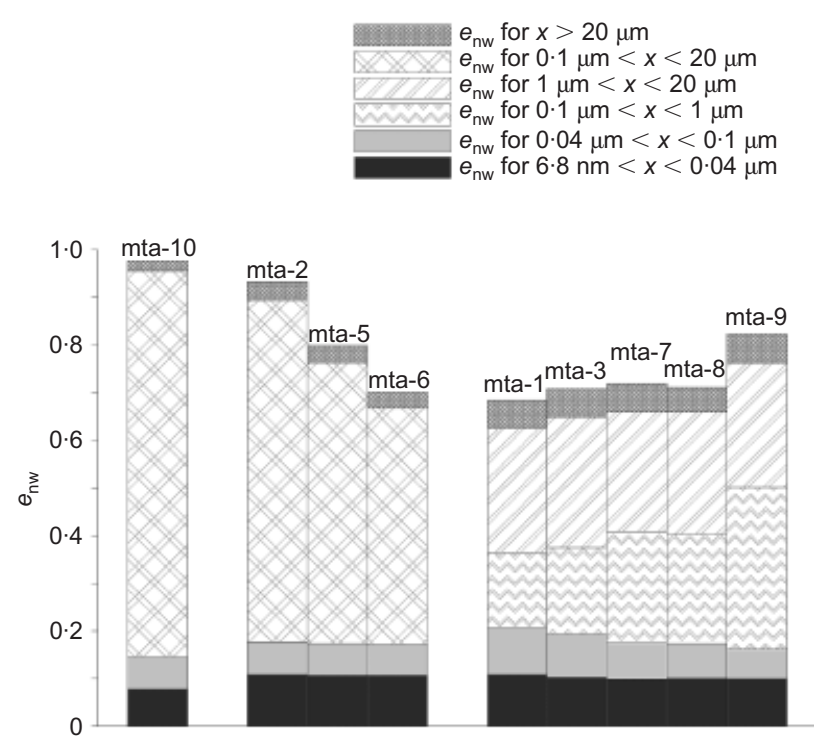

Fig. 17. Summary of volumes of intruded porosity

the same process. This result agrees with findings from previous researchers (Sridharan et al., 1971; Delage \& Lefebvre, 1984; Juang \& Holtz, 1986b; Griffiths \& Joshi, 1989; Lloret et al., 2003; among others), although most of these studies concentrated on the effect of loading or changes in initial water content prior to compaction on microfabric. The reconstituted sample mta-10, on the other hand, displays a reduced volume of intruded mercury $(0.078)$ for this pore size class, suggesting a genuine variation in microfabric at the lower end of the pore size range. Table 5 lists volumes of this porosity measured in all samples.

Volumes of intruded mercury between apparent entrance diameters of $0.04 \mu \mathrm{m}$ and $0.1 \mu \mathrm{m}$ are also shown in Fig. 17, plotted above the previous set of results. The entrance pore diameter of $0 \cdot 1 \mu \mathrm{m}$ corresponds to the value below which the pore size distribution and pore size density functions of all fully hydrated samples were observed to coincide (refer to Fig. 14). The volumes of pore space within this range progressively reduced from 0.099 (mta-1) to 0.061 (mta-9) as the sample hydrated under a nominal load. Volumes in the fully hydrated state, however, remained constant, ranging from 0.069 (mta-2) to 0.066 (mta-6) (refer to Table 5 for a list of all measured values). This observation suggests that although wetting had an effect on the volume of this range of pore sizes, loading in the fully hydrated state to the maximum load considered in this study had no apparent effect. The equivalent intruded volume in the reconstituted sample mta-10 $(0.068)$ is very similar to that observed in the fully hydrated specimens.

In the other range of the spectrum, volumes of intruded

Table 5. Volumes of porosity for each of the pore size categories considered in the study

\begin{tabular}{|c|c|c|c|c|c|c|}
\hline Sample & $6.8 \mathrm{~nm}<x<0.04 \mu \mathrm{m}$ & $0.04 \mu \mathrm{m}<x<0.1 \mu \mathrm{m}$ & $0 \cdot 1 \mu \mathrm{m}<x<1 \mu \mathrm{m}$ & $1 \mu \mathrm{m}<x<20 \mu \mathrm{m}$ & $0 \cdot 1 \mu \mathrm{m}<x<20 \mu \mathrm{m}$ & $x>20 \mu \mathrm{m}$ \\
\hline mta-1 & $0 \cdot 108$ & 0.099 & $0 \cdot 157$ & $0 \cdot 261$ & - & $0 \cdot 060$ \\
\hline mta-2 & $0 \cdot 108$ & 0.069 & - & - & 0.718 & $0 \cdot 038$ \\
\hline mta-3 & $0 \cdot 103$ & 0.091 & $0 \cdot 181$ & $0 \cdot 274$ & - & 0.059 \\
\hline mta-5 & $0 \cdot 106$ & 0.067 & - & - & 0.590 & 0.036 \\
\hline mta-6 & $0 \cdot 106$ & 0.066 & - & - & 0.496 & 0.033 \\
\hline mta-7 & 0.099 & 0.075 & 0.234 & $0 \cdot 251$ & - & $0 \cdot 061$ \\
\hline mta- 8 & $0 \cdot 101$ & $0 \cdot 072$ & $0 \cdot 229$ & $0 \cdot 257$ & - & $0 \cdot 052$ \\
\hline mta-9 & $0 \cdot 100$ & $0 \cdot 061$ & $0 \cdot 340$ & $0 \cdot 261$ & - & $0 \cdot 061$ \\
\hline mta-10 & 0.078 & 0.068 & - & - & $0 \cdot 810$ & 0.020 \\
\hline
\end{tabular}


mercury in pores with apparent diameter larger than $20 \mu \mathrm{m}$ for partly hydrated samples remain relatively constant, ranging between 0.052 and 0.061 (see Fig. 17 and Table 5). The process of hydration (mta-7, mta- 8 and mta-9) down to low values of suction does not seem to have greatly affected the volume of this porosity. However, once the sample reaches the fully hydrated state (mta-2), the volume associated with this porosity decreases slightly to a value of about $0 \cdot 038$. Similar volumes are measured in samples mta$5(0 \cdot 036)$ and mta-6 (0.033). The corresponding volume for mta-10 is 0.02 , which is lower than that exhibited by any of the compacted samples.

The most significant variation in the volume and distribution of pore space between the different samples is found in the range of porosities between $0 \cdot 1 \mu \mathrm{m}$ and $20 \mu \mathrm{m}$. Considering first the partly hydrated samples (mta-1, mta-3, mta-7, mta- 8 and mta-9), by referring to Figs 12 and 15 one can broadly divide this range of pore sizes between those assumed to correspond to the intra-aggregate porosity (pores smaller that $1 \mu \mathrm{m}$ ) and those corresponding to the interaggregate porosity (pores larger than $1 \mu \mathrm{m}$ ). A similar interpretation of pore space is presented, for example, in Lloret et al. (2003). Fig. 17 and Table 5 show that no significant variation exists in the pore space associated with entrance diameters between $1 \mu \mathrm{m}$ and $20 \mu \mathrm{m}$, with values ranging from $0 \cdot 251$ to $0 \cdot 274$. The picture is very different, however, when the smaller porosity $(0 \cdot 1 \mu \mathrm{m}$ to $1 \mu \mathrm{m})$ is compared. In this case, the process of hydration brings about a significant increase in the volume of pores within this category, increasing from 0.157 (mta-1) to 0.34 (mta-9) as the sample is wetted.

Samples in the fully hydrated state, on the other hand, present a single dominant pore entrance diameter, ranging in size from $0.670 \mu \mathrm{m}$ (mta-6) to $1.730 \mu \mathrm{m}$ (mta-2), as shown in Figs 14 and 16. Therefore, in this case, it is possible to consider a single pore class extending between $0 \cdot 1 \mu \mathrm{m}$ and $20 \mu \mathrm{m}$. The corresponding volumes are presented in Fig. 17 and Table 5. It is evident from the figure that the process of hydration causes a significant increase in the volume of pores included within this range: wetting under a nominal load results in a progressive increase in porosity within this size range from 0.418 (mta-1) to 0.718 (mta-2). Furthermore, differences in volume between different samples in the fully hydrated state (mta-2, mta-5 and mta-6) are also associated with changes in this porosity. As the vertical load increases, the volume of this pore class decreases steadily from 0.718 (mta-2) to 0.496 (mta-6). The equivalent porosity displayed by the reconstituted sample mta-10 $(0 \cdot 81)$ is significantly higher than the one measured in the compacted, fully hydrated sample mta-2 $(0 \cdot 718)$.

On the basis of the above results, the following conclusions can be drawn regarding the change of microfabric with changes in load and suction.

(a) Both the application of load and the reduction in suction appear to leave the porosity with equivalent entrance pore diameter smaller than $0 \cdot 1 \mu \mathrm{m}$ and greater than $20 \mu \mathrm{m}$ largely unaltered.

(b) The main effect of hydration is to change the initial bimodal pore size distribution set up by the compaction process into a pore distribution dominated by a single pore size. The equivalent pore diameter of $1 \mu \mathrm{m}$ is assumed to separate intra- from inter-aggregate porosities in the partly hydrated state. For the case of a sample hydrated under a nominal load (mta-2, mta-7, mta-8 and mta-9), this change in fabric is observed to take place at very low values of suction, below $40 \mathrm{kPa}$. A reduction in suction from the initial as-compacted value of approximately $1000 \mathrm{kPa}$ down to $40 \mathrm{kPa}$ is accompanied by a significant increase in the volume of intra-aggregate pores, whereas the volume of interaggregate pores is observed to remain relatively constant.

(c) The main differences between the final fabrics observed in the three samples hydrated along different stress paths (mta-2, mta-5 and mta-6) have to do with (i) the size of the dominant pore size diameter, and (ii) the volume of the porosity with entrance diameters between $0 \cdot 1 \mu \mathrm{m}$ and $20 \mu \mathrm{m}$. As the vertical load is increased, both the diameter of the dominant pore size, as well as the volume associated with this range of pore sizes, decrease.

(d) It is possible to observe differences between a compacted (mta-2) and a reconstituted (mta-10) samples having similar void ratios. Although both samples display a pore size distribution dominated by a single equivalent pore size, the reconstituted sample presents a larger volume of pores associated with diameters between $0 \cdot 1 \mu \mathrm{m}$ and $20 \mu \mathrm{m}$, as well as a smaller dominant entrance pore size diameter.

SCANNING ELECTRON MICROSCOPY OBSERVATIONS

The ESEM image corresponding to the as-compacted sample mta-1 at a magnification factor of $600 \times$ is shown in Fig. 18. Both the aggregates as well as the inter-aggregate voids are clearly visible in the image. Inter-aggregate void diameters are marked in the figure, and these can be seen to be of a similar order of magnitude as those inferred from the MIP data (Fig. 10).

Images corresponding to samples with final states on the LC yield surface, mta-3 and mta-6, are presented in Figs 19 and 20 respectively. These two images have also been taken at a magnification factor of $600 \times$. It is more difficult to identify the same well defined inter-aggregate voids in Fig. 19 as it is in Fig. 18, although the MIP data suggest that these are present. Fig. 20, on the other hand, clearly shows how the process of hydration resulted in the almost complete removal of this large porosity, as suggested by the MIP results (Fig. 11).

Figure 21 presents the ESEM image for sample mta-2. According to the MIP results, this sample displayed a

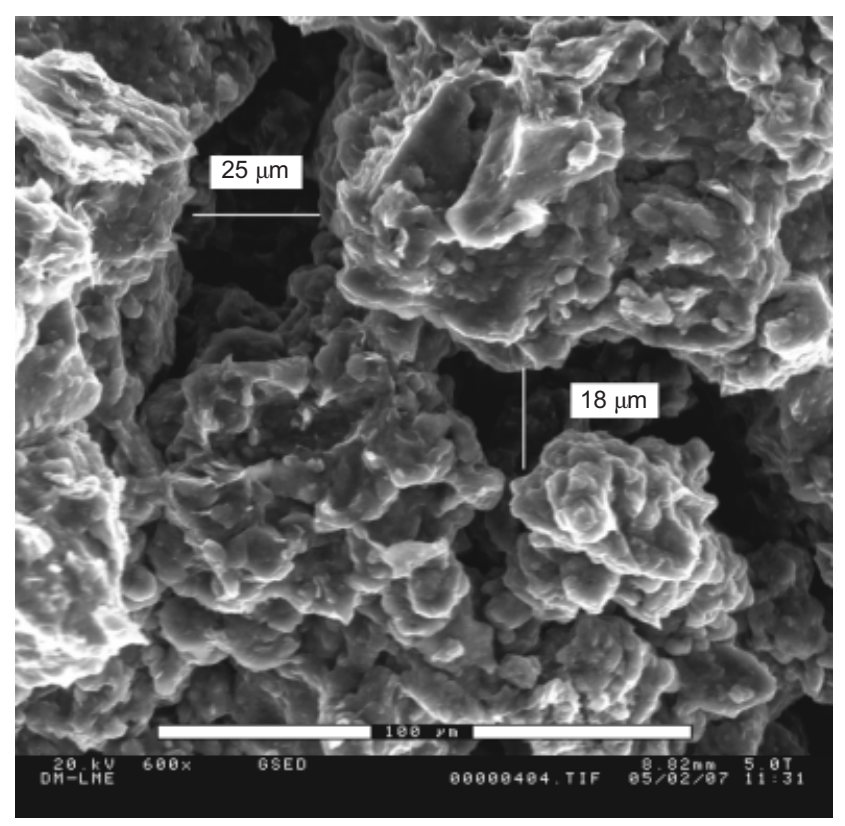

Fig. 18. ESEM image of sample mta-1 


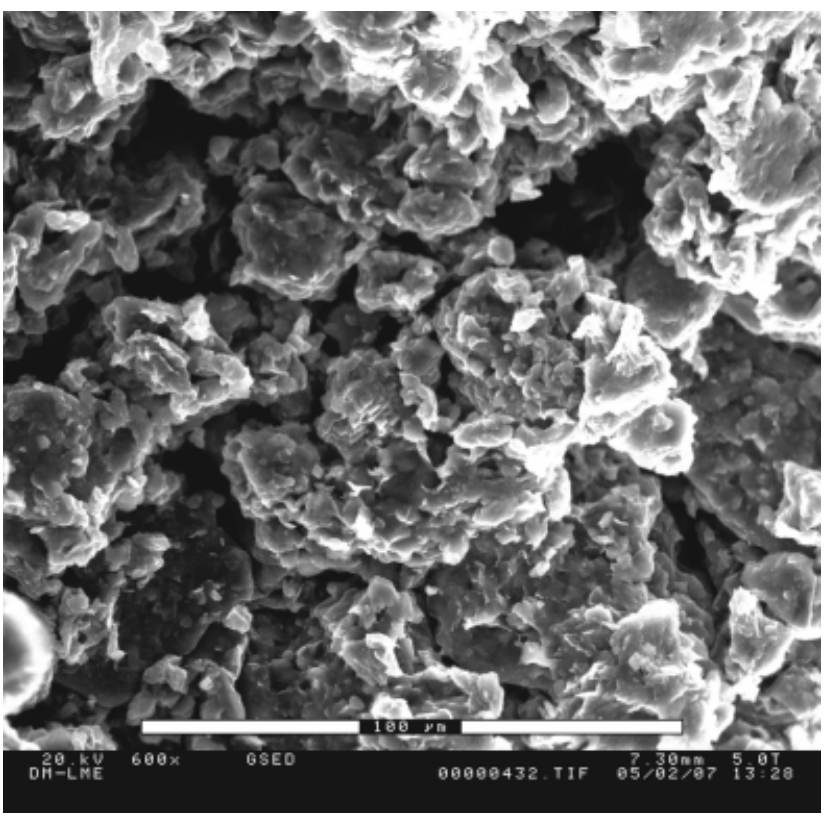

Fig. 19. ESEM image of sample mta-3

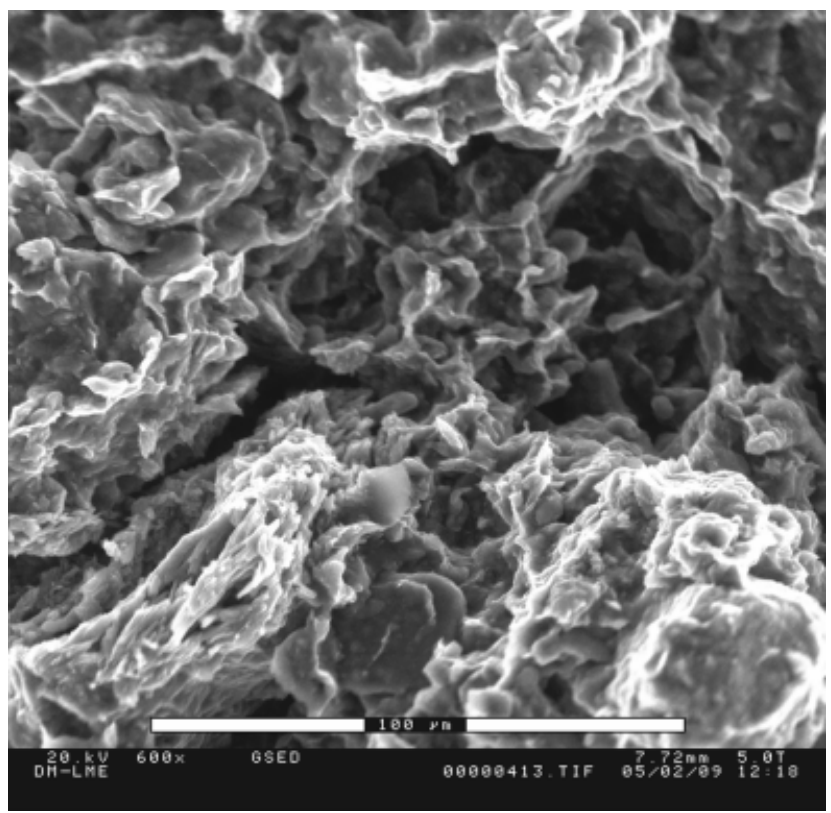

Fig. 20. ESEM image of sample mta-6

homogeneous pore size distribution dominated by a single pore size (Fig. 13). The ESEM image suggests that this is the case.

Finally, comparison between Fig. 21 and Fig. 22, corresponding to samples mta- 2 and mta-10 respectively, shows that a marked difference exists between the fabric of a compacted, fully hydrated sample and that of a reconstituted soil. It is interesting to note that, whereas the MIP results did not suggest such large differences (Fig. 16), the ESEM observations confirm that there is a genuine and significant difference in the fabric of these two samples.

\section{DISCUSSION}

Distribution of pore water

The BExM assumes the microstructural level within the aggregates to remain saturated and therefore volumetric

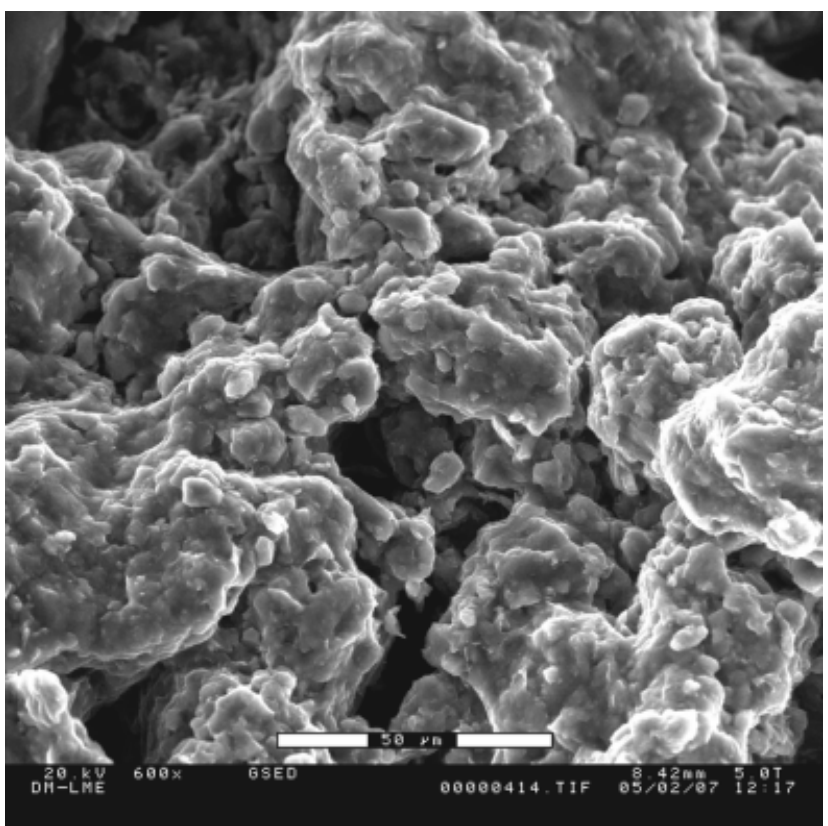

Fig. 21. ESEM image of sample mta-2

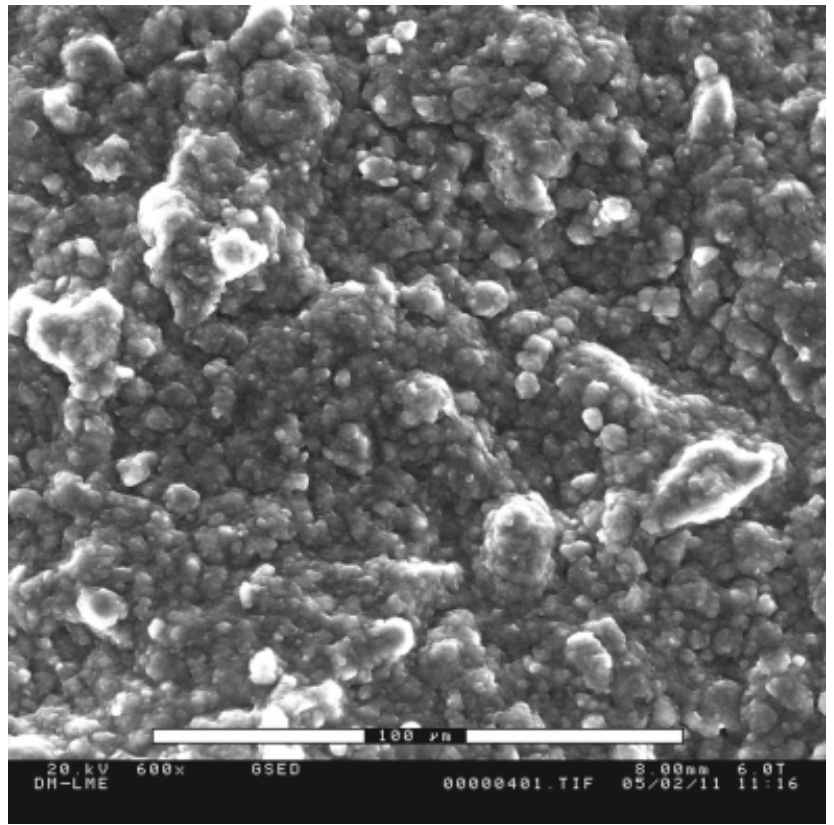

Fig. 22. ESEM image of sample mta-10

deformations at this level to be controlled by the effective stress principle. On the basis of the volume of void space occupied by water, $e_{\mathrm{w}}$, as well as the distribution of pore space obtained from the MIP, it is possible to verify this assumption in the present case. The total volume of the sample, $e_{0}$, can be split between intruded and very thin (non-detected) porosities, given by $e_{\max }$ and the difference $e_{\mathrm{o}}-e_{\max }$ respectively. Additionally, $e_{\mathrm{o}}$ can also be divided between the volume of water, $e_{\mathrm{w}}\left(=e_{\mathrm{o}} S_{\mathrm{r}}\right)$ and the volume of air, $e_{\mathrm{a}}\left(=e_{\mathrm{o}}-e_{\mathrm{w}}\right)$. By assuming the very thin porosity $\left(e_{\mathrm{o}}-e_{\max }\right)$ to remain saturated, it is possible to calculate the volume of intruded pore space occupied by air and water respectively. This has been done and the results are presented in Fig. 23, where the results from Fig. 17 have been re-plotted and the calculated volumes of water have been superimposed.

When drawing Fig. 23, it has been assumed that water first 


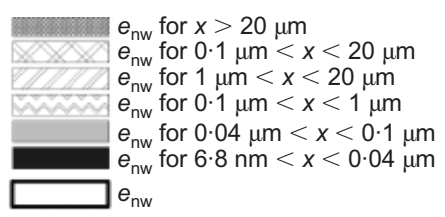

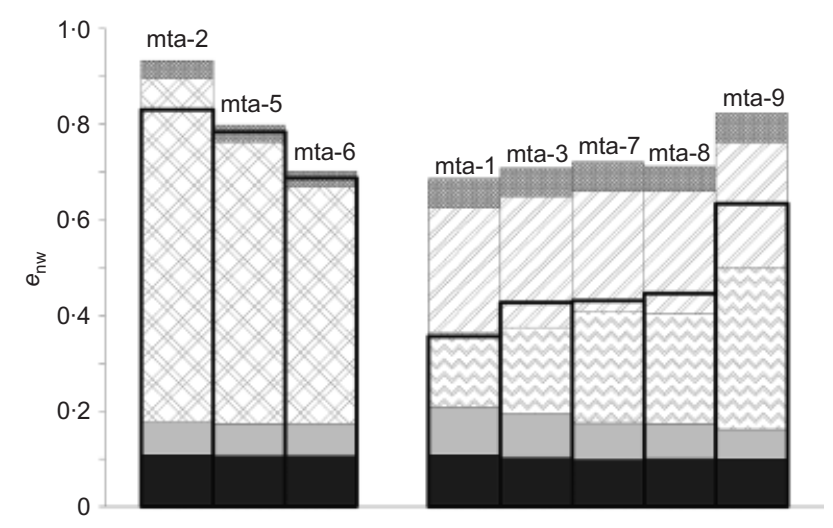

Fig. 23. Comparison between volumes of intruded pore space and estimates of void space occupied by water

occupies the smaller pores. By looking at sample mta-1, one can see that the volume of water coincides with the volume of pore space up to an entrance diameter of $1 \mu \mathrm{m}$, which, and with reference to Fig. 10, is assumed to be the entrance diameter separating intra- from inter-aggregate porosities. The results for mta-3 suggest that some of the larger interaggregate pores are occupied by water. This could be a genuine effect of loading, although it might also reflect experimental uncertainties. If one looks at the results for mta7 and mta-8, it is apparent that during the initial stages of free swelling, most of the water is retained within the aggregates. It is only in the final stages of hydration, when the suction reduces to low values (mta-9), that a significant proportion of the inter-aggregate void space starts to fill up with water.

In Fig. 23 the results for the fully hydrated samples have also been plotted for completeness. Sample mta-2 reached equilibrium at a degree of saturation of $91 \%$, whereas mta-5 and mta- 6 are virtually in their fully saturated state at the end of the hydration stage.

Based on the results presented in Fig. 23 it can therefore be concluded that in the present case the assumption that aggregates start and remain saturated is correct. This result agrees with those presented by Delage et al. (1996) for a compacted silt.

\section{Comparison between free and intra-aggregate porosity}

Delage \& Lefebvre (1984) proposed that the free porosity corresponds to the intra-aggregate porosity, whereas the entrapped porosity gives an indication of the inter-aggregate porosity. This same idea has been adopted by other researchers to interpret MIP results (for example, Romero et al., 1999).

Volumes of free porosity and intra-aggregate porosity associated with an entrance diameter smaller than $0 \cdot 1 \mu \mathrm{m}$ have been plotted together in Fig. 24. Except for mta-1, it can be seen that the agreement is good. Even for mta-1, the difference between both porosities is approximately $0 \cdot 025$. The equivalent entrance pore diameter of $0 \cdot 1 \mu \mathrm{m}$ does not, however, seem to divide the intra- from inter-aggregate porosity in the partly hydrated samples, but rather a higher diameter of $1 \mu \mathrm{m}$ (corresponding to the trough in the pore size density functions shown in Figs 12 and 15). In the case of the fully hydrated samples, the entrance diameter of $0 \cdot 1 \mu \mathrm{m}$ seems to mark the start of a rise in the pore size density function (see Fig. 14). The good agreement between the volume of free

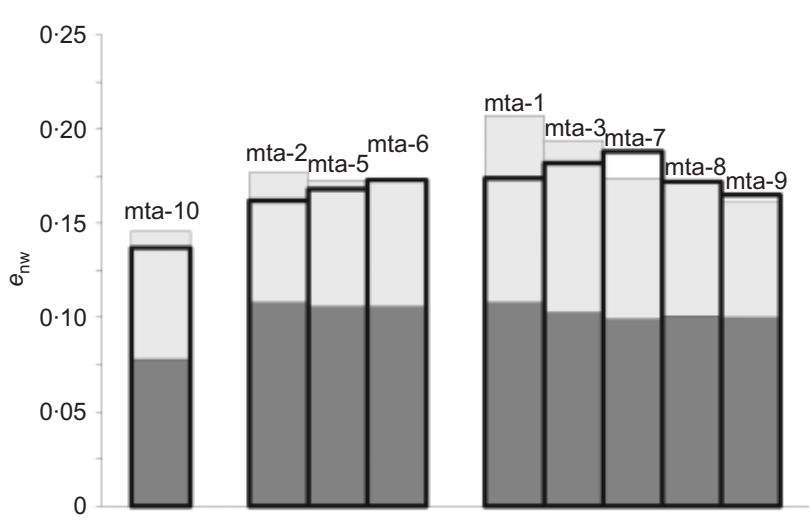

Fig. 24. Comparison between free and intra-aggregate porosities

porosity and pore volume below an entrance diameter of $0 \cdot 1 \mu \mathrm{m}$, which holds even for the reconstituted sample, suggests that free porosity is linked to some fundamental property of the material. However, on the basis of the experimental evidence it is difficult in this instance to draw a direct link between free and intra-aggregate porosity.

\section{The suction decrease coupling function}

The suction decrease coupling function is used in the BExM to link micro- and macrostructural deformations, as shown in Fig. 5. For low values of $p / p_{0}$, this function takes positive values, since it is assumed that wetting at low stresses results in expansion of both the micro- and the macrofabric. At higher values of stress, the function can take negative values, implying associated microfabric expansion with invasion of the macrostructural pore space (and therefore reduction of the macroporosity). The coupling function is based on two levels of structure, corresponding to the intra- and inter-aggregate pore space, which interact in a relatively simple manner. In the present case, the divide between these two structural levels in the partly hydrated state could be assumed to correspond to an equivalent pore diameter of $1 \mu \mathrm{m}$ (Fig. 10), as mentioned earlier.

The results summarised in Fig. 17 show how hydration at low stresses (mta-2, mta-7, mta-8, mta-9) initially results in an increase in both intra- and inter-aggregate porosities; however, wetting eventually results in a homogenisation of the pore space above an entrance diameter of $0 \cdot 1 \mu \mathrm{m}$. Below this diameter, the pore space remains virtually unaffected by the hydration process. In the case of sample mta- 6 , the value of $p / p_{0}$ at which hydration takes place is higher. Wetting at a higher load results, nevertheless, in the same process of homogenisation of pore space above an equivalent entrance diameter of $0 \cdot 1 \mu \mathrm{m}$.

The above results make it difficult to calculate the microand macrostructural volumetric strains associated with the full process of hydration in the manner proposed in Alonso et al. (1999)

$$
\begin{aligned}
\delta \varepsilon_{\mathrm{vol}}^{\mathrm{m}} & =\frac{\Delta e^{\mathrm{m}}}{1+e_{\mathrm{o}}}(\text { microstructural strains }) \\
\delta \varepsilon_{\mathrm{vol}}^{\mathrm{M}} & =\frac{\Delta e^{\mathrm{M}}}{1+e_{\mathrm{o}}}(\text { macrostructural strains })
\end{aligned}
$$

where $\Delta e^{\mathrm{M}}$ and $\Delta e^{\mathrm{m}}$ denote an increase in the inter- and 
intra-aggregate void ratios respectively. In the present case, values of $\Delta e^{\mathrm{m}}$ and $\Delta e^{\mathrm{M}}$ can only be computed for samples in the partly hydrated state. For the case of samples which are fully hydrated, it becomes difficult to define micro- and a macrovoid spaces in a simple way. The above two equations, although suitable for a double porosity structure which remains so during wetting, are not suitable for the case in which hydration causes a marked change in fabric type, as observed in the present case.

The value which the suction decrease coupling function, $f_{D}$ takes for a given $p / p_{0}$ is given by the ratio of macro- to microstructural strains

$$
\frac{\delta \varepsilon_{\mathrm{vol}}^{\mathrm{M}}}{\delta \varepsilon_{\mathrm{vol}}^{\mathrm{m}}}=f_{\mathrm{D}}\left(\frac{p}{p_{\mathrm{o}}}\right)
$$

As neither the micro- nor the macrostructural strains can be computed in the manner proposed, it is believed that in the present case it is not possible to define the value of the suction decrease coupling function corresponding to the fully hydrated state.

On the basis of the results presented in this paper, it would appear that by idealising the fabric in a lightly compacted soil, which displays an initial bimodal pore size distribution, as consisting of two levels of structure which interact in a simple way, as proposed in the BExM, it is not possible to fully capture the actual physical mechanisms taking place during hydration. The double porosity framework has been used successfully to model soil behaviour (see, for example, Lloret et al. (2003)); however, in the present case, it would appear that the different levels of structure within the compacted clay interact in a more complex way than originally envisaged.

\section{Effect of reaching the LC yield surface}

Comparison of the pore size distributions exhibited by samples mta-3 and mta-6 (Fig. 11) shows how changes in fabric associated with reaching and travelling along the LC yield surface are stress path-dependent. This was not originally considered in the formulation of the BExM, where it was assumed that similar variations in fabric would result from yielding along wetting and loading paths. Whereas one would expect the loading of sample mta-3 beyond the maximum applied stress of $550 \mathrm{kPa}$ to result in the progressive reduction of the macropores with equivalent entrance diameter larger than $1 \mu \mathrm{m}$, in agreement with earlier observations reported in the literature (Delage \& Lefebvre, 1984; Griffiths \& Joshi, 1989; Lapierre et al., 1990), reaching the LC yield surface along a wetting path (sample mta-6) resulted in the immediate homogenisation of the pore space above an entrance diameter of $0 \cdot 1 \mu \mathrm{m}$. Although the idea of stress path independency of fabric change might be valid for a granular material, the experimental evidence herein presented suggests this might not be the case for a lightly compacted natural clay.

\section{CONCLUSIONS}

The aim of this study was to gather experimental data which could be used to assess the effect of changes in applied load and suction on the evolution of fabric in a compacted natural clay. It was hoped that the results would serve to compare material behaviour against assumptions made in constitutive models which explicitly consider the role of microfabric in their formulation. Given that the initial fabric set up by the compaction process was observed to consist of aggregates separated by well-defined inter- aggregate pores, the double porosity BExM model was selected for this exercise.

A total of eight samples of London Clay were compacted to the same initial conditions and taken along paths involving wetting and loading. An additional sample was prepared as a slurry and consolidated one-dimensionally. The mechanical response of the compacted soil was determined on the basis of suction controlled oedometer tests, carried out under atmospheric conditions. The fabric of the material at the end of each of the paths was studied using MIP and ESEM techniques. The results were analysed within the context of the mechanical response of the soil.

It was possible to observe some interesting aspects of the evolution of microfabric in the compacted samples during wetting. Following compaction the soil displayed a clear bimodal pore size distribution, characteristic of a fabric composed of aggregates separated by large inter-aggregate voids. However, the process of hydration was found to invariably erase this initial fabric. Regardless of the hydration path followed-free swell, confined wetting at constant volume, and wetting under a high vertical load - the final fabric associated with zero suction was dominated in all cases by a single pore size. The analysis of evolution of fabric with suction was only carried out in samples undergoing free swelling. In this case, the transition between an aggregate and a matrix structure was found to take place as the suction was reduced from $40 \mathrm{kPa}$ to $0 \mathrm{kPa}$. The initial reduction in suction from $1000 \mathrm{kPa}$ to $40 \mathrm{kPa}$ was found to preserve the original aggregate structure.

In the initial as-compacted state, and on the basis of the shape of the pore size density function, the boundary between intra- and inter-aggregate pore space was estimated to coincide with an equivalent entrance pore diameter of $1 \mu \mathrm{m}$. The process of free swelling was observed to result in $(a)$ a minor reduction in the porosity associated with an entrance pore diameter smaller $0 \cdot 1 \mu \mathrm{m}$, (b) a slight reduction in the porosity associated with an entrance pore diameter greater than $20 \mu \mathrm{m}$ and $(c)$ an important increase in the porosity associated with entrance diameters between $0 \cdot 1 \mu \mathrm{m}$ and $20 \mu \mathrm{m}$. It was within this last class that the change between a double and a single structure was observed.

It was found that the change in fabric resulting from the process of hydration made it difficult to calculate the volumetric micro- and macrostrains as given in Alonso et al. (1999), and hence the value of the suction decrease coupling function. It is believed that in the present case the microstructural changes which take place as the sample hydrates are more complex than those proposed in the double structure framework.

Comparison of the fabric of two samples which yielded along the LC yield surface (Alonso et al., 1990), one following a loading at constant moisture content path, the other a path involving loading and wetting, revealed the changes in fabric to be stress path-dependent. Whereas loading would be expected to cause a reduction in the size and volume of the large inter-aggregate pores, wetting, as mentioned earlier, was seen to erase the original aggregate structure.

It has been assumed by some authors that the free porosity, as derived from an intrusion-extrusion cycle in the MIP, gives an indication of the volume of intra-aggregate porosity (Delage \& Lefebvre, 1984). However, in the present study, this has not been found to be the case. Although the volume of free porosity coincided with the volume of pores associated with an entrance diameter smaller than $0 \cdot 1 \mu \mathrm{m}$, in the partly hydrated samples, displaying a bimodal pore side density function, the transition between micro- and macrovoids is interpreted to be given by a larger pore diameter of $1 \mu \mathrm{m}$, as mentioned above. 
Comparison of volumes of water and volumes of intraaggregate porosity showed that, in the compacted state, the aggregates are in a saturated state. This agrees with previous observations and supports the assumption, included in the formulation of the BExM, that the principle of effective stress can be applied to model the volumetric behaviour of these aggregates.

\section{ACKNOWLEDGEMENTS}

The fabric studies were carried out with the financial support from the Royal Academy of Engineering (UK), the Soil Mechanics Section at Imperial College London, and Geotechnical Observations Ltd. The first author would like to express his gratitude to the members of the Soil Mechanics Group at the Universidad Politécnica de Cataluña for their invaluable help while carrying out this study.

\section{NOTATION \\ $e_{\mathrm{ex}}$ volume of mercury remaining within the sample at the end of the extrusion stage \\ $e_{\max }$ maximum volume of intruded mercury at the end of the intrusion stage \\ $e_{\min }$ minimum volume of intruded mercury after applying initial pressure and prior to the start of the intrusion stage \\ $e_{\text {nw }}$ cumulative intruded void ratio \\ $e_{\mathrm{o}}$ initial void ratio \\ $e_{\mathrm{W}}$ specific water volume minus the volume of solid particles \\ $P_{\mathrm{Hg}}$ total (absolute) applied pressure \\ $x$ equivalent entrance pore diameter \\ $x_{\mathrm{m}}$ equivalent entrance pore diameter at midpoint of each class width \\ $\varepsilon^{\mathrm{M}}$ macrostructural strains \\ $\varepsilon^{\mathrm{m}} \quad$ microstructural strains \\ $\sigma_{\mathrm{Hg}} \quad$ surface tension of the non-wetting fluid \\ $\theta_{\text {nw }} \quad$ contact angle between the non-wetting fluid and the pore walls}

\section{REFERENCES}

Ahmed, S., Lovell, C. W. \& Diamond, S. (1974). Pore sizes and strength of compacted clay. ASCE J. Geotech. Engng 100, No. 4, 407-425.

Alonso, E. E. (1998). Keynote lecture: modelling expansive soil behaviour. Proc. 2nd Int. Conf. on Unsaturated Soils, Beijing 1, 37-70.

Alonso, E. E., Gens, A. \& Hight, D. W. (1987). Special problem soils. General report. Proc. 9th Eur. Conf. Soil Mech. Found. Engng, Dublin 3, 1087-1146.

Alonso, E. E., Gens, A. \& Josa, A. (1990). A constitutive model for partially saturated soils. Géotechnique 40, No. 3, 405-430.

Alonso, E. E., Vaunat, J. \& Gens, A. (1999). Modelling the mechanical behaviour of expansive clays. Engng Geol. 54, 173-183.

Colmenares-Montanez, J. E. (2002). Suction and volume changes of compacted sand-bentonite mixtures. $\mathrm{PhD}$ thesis, Imperial College, London.

Delage, P. \& Lefebvre, G. (1984). Study of the structure of a sensitive Champlain clay and of its evolution during consolidation. Can. Geotech. J. 21, 21-35.

Delage, P. \& Graham, J. (1995). The mechanical behaviour of unsaturated soils. Proc. 1st Int. Conf. Unsaturated Soils, Paris 3, $1223-1256$.

Delage, P., Tessier, D. \& Marcell-Audiguier, M. (1982). Use of the Cryoscan apparatus for observation of freeze-fractured planes of a sensitive Quebec clay in scanning electron microscopy. Can. Geotech. J. 19, 111-114.

Delage, P., Audiguier, M., Cui, Y. J. \& Howat, M. D. (1996). Microstructure of a compacted silt. Can. Geotech. J. 33, 150-158.

Delage, P., Marcial, D., Cui, Y. J. \& Ruiz, X. (2006). Ageing effects in a compacted bentonite: a microstructure approach. Géotechnique 56, No. 5, 291-304.

Diamond, S. (1970). Pore size distributions in clays. Clays Clay Miner. 18, 7-23.
Dineen, K. \& Burland, J. B. (1995). A new approach to osmotically controlled oedometer testing. Proc. 1st Int Conf. Unsaturated Soils, Paris 2, 459-465.

Garcia-Bengochea, I., Lovell, C. W. \& Altschaeffl, A. G. (1979). Pore distribution and permeability of silty clays. J. Sol Mech. Found. Div. ASCE 105, No. 7, 839-856.

Gasparre, A. (2005). Advanced laboratory characterisation of London Clay. $\mathrm{PhD}$ thesis, Imperial College, London.

Gens, A. \& Alonso, E. E. (1992). A framework for the behaviour of unsaturated expansive clays. Can. Geotech. J. 29, 1013-1032.

Griffiths, F. J. \& Joshi, R. C. (1989). Change in pore size distribution due to consolidation of clays. Géotechnique 39, No. 1, 159-167.

Juang, C. H. \& Holtz, R. D. (1986a). A probabilistic permeability model and the pore size density function. Int. J. Numer. Anal. Methods Geomech. 10, 543-553.

Juang, C. H. \& Holtz, R. D. (1986b). Fabric, pore size distribution, and permeability of sandy soils. J. Geotech. Engng, ASCE 112, No. 9, 855-868.

Lapierre, C., Leroueil, S. \& Locat, J. (1990). Mercury intrusion and permeability of Louiseville clay. Can. Geotech. J. 27, 761-773.

Lloret, A., Villar, M. V., Sanchez, M., Gens, A., Pintado, X. \& Alonso, E. E. (2003). Mechanical behaviour of heavily compacted bentonite under high suction changes. Géotechnique 53, No. 1, 27-40.

Monroy, R. (2006). The influence of load and suction changes on the volumetric behaviour of compacted London Clay. $\mathrm{PhD}$ thesis, Imperial College, London.

Monroy, R., Ridley, A., Dineen, K. \& Zdravkovic, L. (2007a). The suitability of the osmotic technique for the long term testing of partly saturated soils. Geotech. Testing J. 30, No. 3, 220-226.

Monroy, R., Zdravkovic, L. \& Ridley, A. (2007b). Fabric changes in compacted London Clay due to variations in stress and suction. Experimental unsaturated soil mechanics. Springer proceedings in physics 112 (ed. T. Schanz), pp. 41-48. Weimar: Springer.

Monroy, R., Zdravkovic, L. \& Ridley, A. (2008). Volumetric behaviour of compacted London Clay during wetting and loading. Proc. 1st Eur. Conf. Unsaturated Soils, Durham, 315-320.

Ridley, A. M. \& Burland, J. B. (1995). A pore water pressure probe for the in situ measurement of a wide range of soil suctions. Proceedings of the international conference on advances in site investigation practice, pp. 510-520. London: ICE.

Romero, E. (1999). Characterization and thermo-hydro-mechanical behaviour of unsaturated Boom clay: an experimental study. $\mathrm{PhD}$ thesis, Universitat Politecnica de Catalunya, Barcelona, Spain.

Romero, E., Gens, A. \& Lloret, A. (1999). Water permeability, water retention and microstructure of unsaturated compacted Boom clay. Engng Geol. 54, 117-127.

Saiyouri, N., Hicher, P. Y. \& Tessier, D. (1998). Microstructural analysis of highly compacted clay swelling. Proc. 2nd Int. Conf. Unsaturated Soils, Beijing 1, 119-124.

Saiyouri, N., Hicher, P. Y. \& Tessier, D. (2000). Microstructural approach and transfer water modelling in highly compacted unsaturated swelling clays. Mech. Cohes. Frict. Mater. 5, 41-60.

Saiyouri, N., Tessier, D. \& Hicher, P. Y. (2004). Experimental study of swelling in unsaturated compacted clays. Clay Miner. 39, 469-479.

Shackel, B. (1970). The compaction of uniform, replicate soil specimens. J. Aust. Road Res. Board 4, 12-31.

Simms, P. H. \& Yanful, E. K. (2004). A discussion of the application of mercury intrusion porosimetry for the investigation of soils, including an evaluation of its use to estimate volume change in compacted clayey soils. Géotechnique 54, No. 6, $421-426$

Sridharan, A., Altschaeffl, A. G. \& Diamond, S. (1971). Pore size distribution studies. J. Soil Mech. Found. Div. ASCE 97, No. 5, $771-787$.

Thom, R., Sivakumar, R., Sivakumar, V., Murray, E. J. \& Mackinnon, P. (2007). Pore size distribution of unsaturated compacted kaolin: the initial states and final states following saturation. Géotechnique 57, No. 5, 469-474.

Washburn, E. W. (1921). Note on a method of determining the distribution of pore sizes in a porous material. Proc. Nat. Acad. Sci. U.S.A. 7, 115-116.

Wheeler, S. J. (1991). An alternative framework for unsaturated soil behaviour. Géotechnique 41, No. 2, 257-261. 